\title{
A MORPHOLOGICAL, ISOENZYMATIC AND BEHAVIOURAL STUDY OF TEN POPULATIONS OF ANOPHELES (NYSSORHYNCHUS) ALBITARSIS LYNCH-ARRIBALZAGA, 1878 (DIPTERA: CULICIDAE) INCLUDING FROM THE TYPE-LOCALITY - BARADERO, ARGENTINA
}

\author{
MARIA GORETI ROSA-FREITAS; LEONIDAS M. DEANE * \& HOOMAN MOMEN
}

\begin{abstract}
Instituto Oswaldo Cruz, Departamento de Bioquímica e Biologia Molecular *Departamento de Entomologia,
\end{abstract} Caixa Postal 926, 20001, Rio de Janeiro, RJ, Brasil

Anopheles (Nyssorhynchus) albitarsis Lynch-Arribálzaga, 1878 shows morphological and behavioural variations which results in it being sometimes considered as a major malaria vector and at other times as playing no important role in epidemiology. With the aim of clarifying the taxonomy of the species, comparative morphological and isoenzymatic studies were made in populations from the type-locality, Baradero, Argentina and from 9 different localities in Brazil. Morphological studies consisted of the observation of eggs in scanning electron microscopy, of complete chaetotaxy of larvae and pupae and of the detailed drawing of male and female adults. Only Guajará-Mirim and Rio Branco populations, described previously as Anopheles deaneorum sp.n., showed morphological differences. Isoenzymes were studied using 4th instar larvae homogenate and agarose gel electrophoresis. Eleven enzymatic loci were analyzed. By calculation of Nei's Genetic Distance (D), the populations could be separated into 5 groups: i) Baradero, ii) Marajó, iii) Boa Vista, iv) Angra, Itaguat and Paraipaba and v) Guajará-Mirim and Rio Branco. These groups belong to 2 major clusters called I and II, separated by $D=0.345$. In the I cluster are groups $i$, ii and iii and in II cluster iv and v. In I, $D=0.246$ separates $i$ and ii from iii, while $i$ is separated by $D=0.181$ from ii. In $I, D=0.223$ between iv and $v$. Only the population of group $v$ could be distinguished morphologically from the others, leading to the description of an independent species An. deaneorum.

Key words: Anopheles (Nyssorhynchus) albitarsis - Anopheles deaneorum - mosquito - isoenzymes Culicidae

Anopheles albitarsis displays morphological and behavioural variations that suggest it is a complex of cryptic species. The mosquito has a wide distribution in the New World, extending from northern Guatemala to northern Argentina. In this range albitarsis is sometimes endophilic, sometimes zoophilic and possesses variable amount of black in the 2 nd hindtarsomere. Besides morphological variability and different feeding preferences, controversy exists concerning malaria transmission in the different localities where albitarsis was found. Based on the dissection of stomach and salivary glands and on the epidemiological data, albitarsis was sometimes regarded as one of the main vectors of malaria while in other areas it was

This work was supported by CNPq, FAPERJ, SUCAM, and UNDP/World Bank/ WHO Special Programme for Research and Training in Tropical Diseases.

Received 12 February 1990.

Accepted 2 April 1990. considered as without importance in transmission. Studies on natural infection previous to Root (1926), when An. darlingi had not yet been described, mostly refer to all anophelines with the last 3 hindtarsomeres entirely white as argyritarsis (Godoy \& Pinto, 1923; Boyd, 1926). Probably those findings mainly refer to An. darlingi. Godoy et al. (1930) found, in Baixada Fluminense (Rio de Janeiro State lowlands), an albitarsis specimen full of sporozoites in the salivary glands. Kumm (1932) observed endophilic albitarsis in Salvador, Bahia State and considered the mosquito a local vector as $5.8 \%$ of the stomachs had oocysts. Cadena (1938) in Colombia, dissecting albitarsis found $0.4 \%$ of salivary glands positive in Barrancabermeja and $2.5 \%$ of stomachs with oocysts in Puerto Salgar. He concluded that the mosquito was a good vector in these 2 localities. Gabaldón (1940) in Venezuela (Apure River Region) observed albitarsis feeding day and night. 
Coutinho (1942) in Barra da Tijuca, Rio de Janeiro State, found high morphological variability among albitarsis specimens. The general aspect and the dark portion of the 2 nd hindtarsomere varied significantly, with many intermediary aspects. Nevertheless all morphotypes had endophilic behaviour, identical capacity for infection and a mosaic in the exochorion of the eggs. Out of 673 specimens, Coutinho found $27(4.1 \%)$ with oocysts and 1 $(0.1 \%)$ with sporozoites. For that author, albitarsis had an important role in malaria transmission in Rio de Janeiro. However, Freitas (1942), in the same locality, considered albitarsis as playing a secondary role as it was not found in dwellings and had low infection rates $(7.7 \%$ with oocysts). In this locality, Barra da Tijuca, 4 decades later an urban and malaria-free area, Lourenço-de-Oliveira \& Heyden (1986) observed a very exophilic and zoophilic albitarsis population.

In the Paraíba Valley, São Paulo State, Fonseca \& Unti (1943) verified typical and atypical forms related to what was called, var. braziliensis that rarely invaded dwellings. In an experimental infection they recorded the population susceptibility to Plasmodium vivax which developed to sporozoites. A highly endophilic and anthropophilic population of albitarsis was seen by Schiavi (1945) in Iguape, São Paulo State, a malaria endemic area. Oocysts were found in $8.3 \%$ and sporozoites in $3.3 \%$ of the specimens dissected. Based on these characteristics it was incriminated as a vector in the region. The same was found by Coutinho (1946) in Baixada Fluminense. A highly endophilic, anthropophilic and good malaria vector that had 50 to $70 \%$ of black in the 2 nd hindtarsus and a mosaic in the egg exochorion. Galvão \& Damasceno (1944) related a malaria epidemic which occurred years earlier in $\mathrm{Ca}$ choeira do Arari, Marajó Island, to the highly endophilic albitarsis present in that locality.

In the 1940's Galvão \& Damasceno divided the species into 2 subspecies: Anopheles albitarsis albitarsis Lynch-Arribálzaga, 1878, zoophilic with more than $50 \%$ black in the 2 nd hindtarsomere, not involved in malaria transmission and Anopheles albitarsis domesticus Galvão \& Damasceno, 1944, endophilic, with less than $50 \%$ black in the 2nd hindtarsomere, considered a good malaria vector. However there soon appeared populations with characteristics which did not fit in this division.
Deane et al. (1948) working in the northeast and Amazon Regions of Brazil, found 3 different types of albitarsis. Linthicum (1988), based on morphology and behaviour, divided northern and southern populations in Anopheles marajoara and Anopheles albitarsis respectively. For Rios et al. (1984) the percentage of dark scales in the 2nd hindtarsomere, the pilosity of male genitalia anal lobe and the feeding preferences could not be used to separate any of 18 populations they studied. Based on these controversies we decided to study morphologically and isoenzymatically Anopheles albitarsis populations involved in the discussion, including a population from the type-locality.

\section{MATERIALS AND METHODS}

Comparative catches were carried out for evaluating feeding preferences in the typelocality, Baradero, Buenos Aires Province, Argentina and in 9 localities in different regions of Brazil. Females were transferred to the laboratory for rearing and for detailed morpho. logical characterization of the 4 stages: eggs, larvae, pupae and adults. Isoenzymatic profiles were studied in the 4th instar larvae.

Behaviour - Comparative catches were carried out at sunset indoors and outdoors, in human and animal baits in the 9 Brazilian localities (Fig. 1): São Borja, 28०39'30"S, $56^{\circ} 00^{\prime} 16^{\prime \prime} \mathrm{W}$, Rio Grande do Sul State; Angra

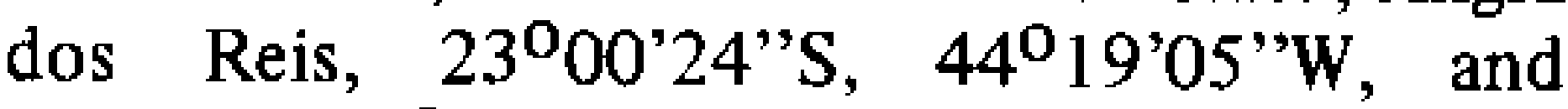

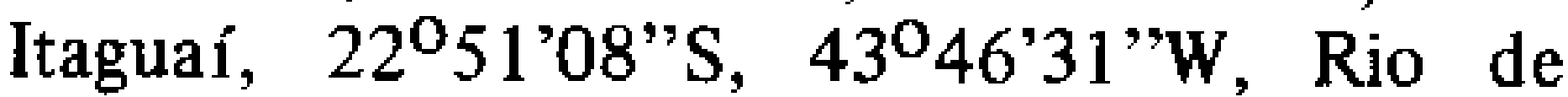
Janeiro State; Guajará-Mirim, 1046'59's, $65^{\circ} 20$ '22"W, Rondonia, State; Rio Branco, 09 $58^{\prime} 29^{\prime \prime} \mathrm{S}, 67^{\circ} 48^{\prime} 36^{\prime \prime} \mathrm{W}$, Acre State; Itaitu.

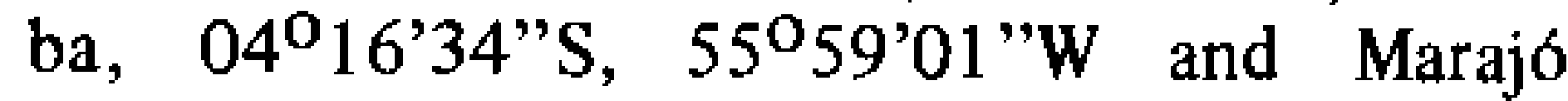
Island, $01^{\circ} 00^{\prime} 41^{\prime \prime} \mathrm{S}, 48^{\circ} 57^{\prime} 48^{\prime} ' \mathrm{~W}$, Pará State; Paraipaba, $03^{\circ} 26^{\prime} 22^{\prime \prime} \mathrm{S}, \quad 39^{\circ} 08^{\prime} 54^{\prime \prime} \mathrm{W}$, Ceará State and Boa Vista, 02 $49^{\circ} 14^{\prime \prime} \mathrm{N}, 60^{\circ} 40^{\prime} 24$ ''W, Roraima State. In Baradero (33 $50^{\circ} \mathrm{S}, 59^{\circ}$ 30 'W) captures were performed in a Shannon's trap using a calf as bait.

Females were identified and separated individually to lay eggs. They were blood fed and observed daily for oviposition. When the eggs were laid a part was frozen for morphology and the rest were put in enamel bowls with dechlorinized water for larval eclosion. Larvae were fed daily with autoclaved crushed and sifted dog food (Kanina, Purina) until 4th stage, when a part was frozen for isoenzymes, 
a part was put in $\mathrm{KOH} 10 \%$ for morphology and the rest were allowed to develop to pupae. When adults emerged, pupal exuviae were put in creosote for morphology and male and female adults were killed with chloroform and pinned.

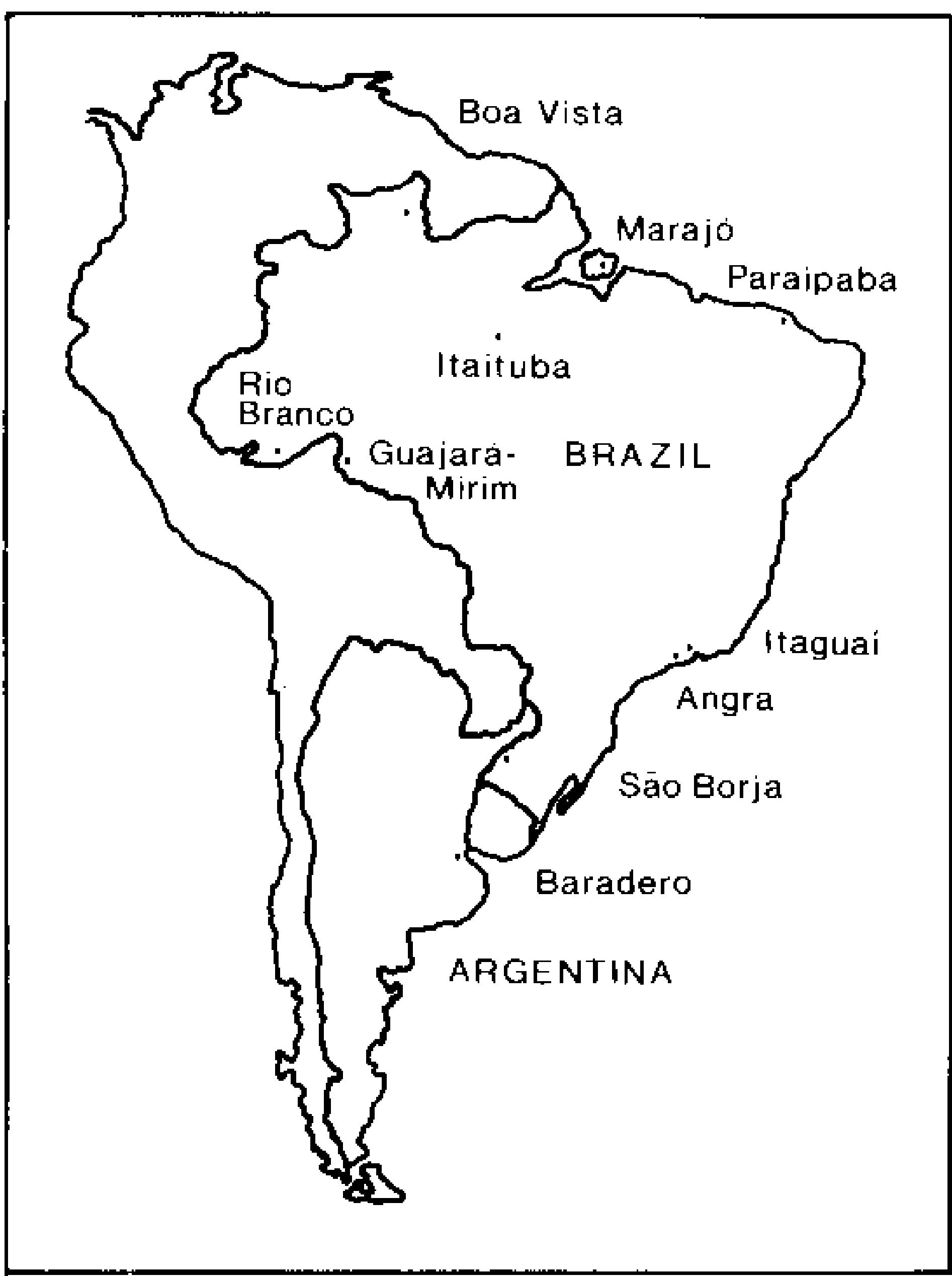

rig. 1: localities where mosquito collections were performed.

Morphology - Eggs from all 10 populations were observed by electron scanning microscopy (JEOL 25 SII - Institute of Biophysics Carlos Chagas Filho, Federal University of Rio de Janeiro) and photographed at a magnification of $200 \mathrm{X}$ to $15,000 \mathrm{X}$ in dorsal, ventral and lateral positions. Thirty larvae and 30 pupal exuviae per locality (10 per type of capture) were mounted in Canadá balsam for complete chaetotaxy of their 180 and 100 pairs of setae respectively. Detailed drawing of adults included general external appearance, cibarial armature and male and female genitalia. Banding wing patterns were observed in 30 specimens per locality ( 10 per type of capture) and measures of the black extension in the 2nd hindtarsomere were made in all pinned specimens.

Isoenzymes - Multilocus enzyme electrophoresis was carried out in agarose gels as described by Momen \& Salles (1985) with the following modifications. Fourth instar larvae were homogeneized using a glass rod and plastic microtitre plate. The homogenate was applied directly to the agarose gel using the sample application foil. The enzymes studied together with the buffers and staining systems used for each enzyme are given in Tables $I$ and II. Analysis of the electrophoretic data was as described previously (Rosa-Freitas, 1989).

\section{RESULTS}

Behaviour - The number of females caught in animal and human baits as well as indoors are shown in Table III. The results will be discussed below in relationship with morphology and distribution.

Morphology - The nomenclature used is that of Harbach \& Knight $(1980,1981)$. A detailed description of eggs in the population from the type-locality has been given previously in the election of a neotype for the species (Rosa-Freitas \& Deane, 1989). In the other populations some variation in the size and number of the star-shaped tubercles on the endochorion was observed by electron microscopy. The number of eggs examined however was insufficient for a statistically significant analysis of this variation. No other differences in the morphology of the eggs from the different localities were found.

A complete chaetotaxy in all 180 pairs of setae in the larvae was carried out. Besides fluctuations in branching of setae, a distinction was found only in the outer anterior clypeal hairs. Larvae from Guajará-Mirim and Rio Branco had these clypeal hairs definitely branched contrary to those from the type-locality, Baradero, and the other 7 Brazilian localities in which they are aciculate. This difference together with some other characteristics in adult specimens from these 2 localities, led to the description of a new species in the albitarsis complex, Anopheles deaneorum (Rosa-Freitas, 1989). In fact, in a recent visit to Costa Marques one of us had the opportunity of collecting deaneorum and albitarsis at the same time. In this area the differences are sufficient to permit entomologists working with the United States Army Medical Research Unit (Dr Terry Klein) to separate regularly the 2 species without the help of a stereomicroscope and breed them as separate colonies. 
TABLE I

Lysis buffer, agarose gel, dyes and buffer solutions used in agarose gel eletrophoresis

1 - Lysis buffer

Tris $\mathrm{HCl} 0,5 \mathrm{M} \mathrm{pH} 8,0 \ldots \ldots \ldots \ldots \ldots \ldots \ldots$

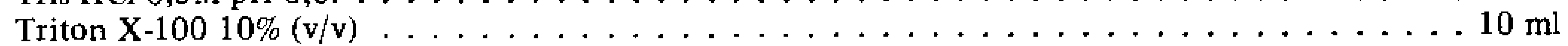

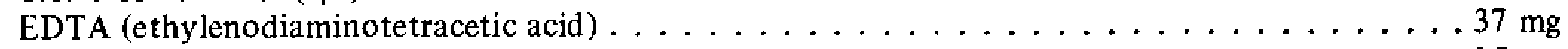

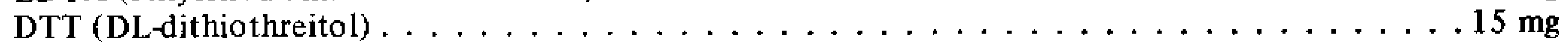

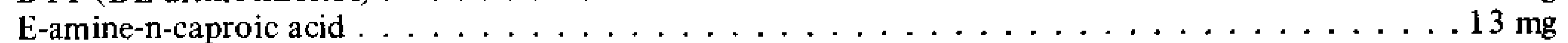

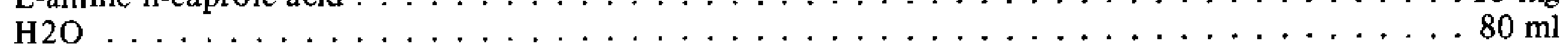

2 - Agarose gel

Agarose $($ HGT - SEAKEM or type V-SIGMA) $\ldots \ldots \ldots \ldots \ldots \ldots \ldots \ldots$

Buffer solution $(4) \ldots \ldots \ldots \ldots \mathrm{ml}) \quad \ldots \ldots \mathrm{ml}$

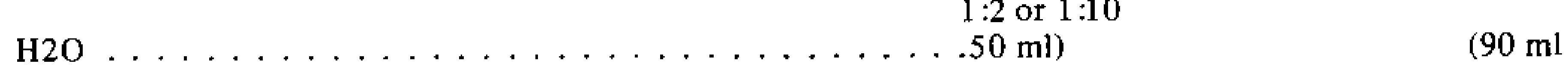

3 - Tracking solution

Bromophenol Blue $\ldots \ldots \ldots \ldots \ldots \ldots \ldots \ldots \ldots \ldots \ldots \ldots$

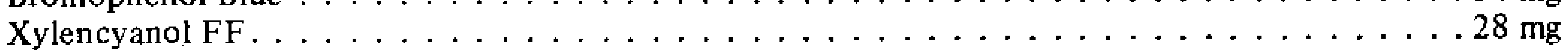

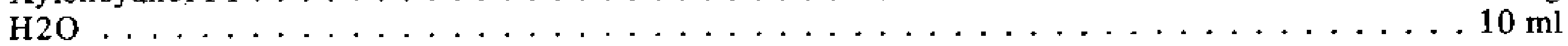

4 - Buffer solutions

Buffer System

Electrodes

$\mathrm{pH}$ adjusted with $\mathrm{NaOH}$

Gel

$10 \mathrm{M}$ or HCL $10 \%$
a) TRIS Maleic $0,1 \mathrm{M}$
$0.01 \mathrm{M}$ EDTA
$0.01 \mathrm{M} \mathrm{MgCl} 2$

b) Phosphate $0,2 \mathrm{M}$

c) TRIS $0,2 \mathrm{M}$ - Citric $0,14 \mathrm{M}$

\begin{tabular}{|c|c|c|}
\hline $\begin{array}{l}\text { Tris } \\
\text { Maleic Acid } \\
\text { EDTA } \\
\text { pH } 7,4\end{array}$ & $\begin{array}{c}12,10 \mathrm{~g} / 1 \\
11,61 \\
3,72\end{array}$ & $\begin{array}{l}\text { Dilute } \\
\text { electrode } \\
\text { buffer } 1: 10\end{array}$ \\
\hline $\begin{array}{l}\mathrm{Na} 2 \mathrm{HPO} 4 \\
\mathrm{NaH} 2 \mathrm{PO} 4 \\
\mathrm{pH} 8,0\end{array}$ & $\begin{array}{r}28.40 \\
1,11\end{array}$ & $\begin{array}{l}\text { Dilute } \\
\text { electrode } \\
\text { buffer } 1: 10\end{array}$ \\
\hline $\begin{array}{l}\text { Tris } \\
\text { Citric Acid } \\
\text { pH 8,1 }\end{array}$ & $\begin{array}{l}41,6 \\
16,5\end{array}$ & $\begin{array}{l}\text { Dilute } \\
\text { electrode } \\
\text { buffer } 1: 10\end{array}$ \\
\hline
\end{tabular}

Complete chaetotaxy was also performed in 30 pupae per locality. No important differences were seen. In a few setae some abnormalities appeared. Seta 0 -VII had its point of insertion displaced downwards from the normal position in specimens from São Borja, Angra and Paraipaba. Seta 10-VI which did not appear in most of the specimens, was present in rare specimens from São Borja, Itaguaí, Itaituba and Boa Vista. Doubled setae (seta with a twin inserted at side) appeared in some specimens from Angra dos Reis (setae 10.V and $11-\mathrm{V}$ ), Itaituba (10-IV and $10-\mathrm{V}$ ) and Boa Vista (10-III and 11-III, 10-IV and 11-IV and 10-V and 11-V). Tables with complete chaetotaxy of larvae and pupae for all populations have already been published (RosaFreitas, 1988) and will not be presented here as they show no differences, except for those observed in the larvae of deaneorum.

Adults showed differences in general colour, colour of pale wing scales, the banding pattern of wing spots, percentage black in the 2nd hindtarsomere and in the insertion of posterolateral tufts of scales in abdominal tergites. Male and female palpomeres had some variation in the amount of black and white scales. The most frequent pattern is essentially the same as previously described in neotype election (Rosa-Freitas \& Deane, 1989). 
TABLE II

Revelation systems for 10 enzymes used in agarose gel electrophoresis

\begin{tabular}{|c|c|c|c|c|c|c|c|c|c|c|c|}
\hline Enzyme & $\begin{array}{l}\text { Buffer } \\
\text { system }\end{array}$ & $\mathrm{V} / \mathrm{cm}$ & $\begin{array}{l}\text { Time } \\
\text { (min) }\end{array}$ & $\begin{array}{l}\text { Staining } \\
\text { buffer } 0.5 \mathrm{M} \\
\text { TRIS-HCL }\end{array}$ & $\begin{array}{l}\mathrm{H} 2 \mathrm{O} \\
(\mathrm{ml})\end{array}$ & Coenzymes & $\begin{array}{l}\text { Linking } \\
\text { enzymes }\end{array}$ & Substrates & Activators & \multicolumn{2}{|c|}{$\begin{array}{l}\text { Visualization } \\
\text { method }\end{array}$} \\
\hline $\begin{array}{l}\text { MDH } \\
1.1 .1 .37\end{array}$ & b & 10 & 90 & $4 \mathrm{ml} \mathrm{pH} 8.0$ & 5 & $\begin{array}{l}8 \mathrm{mg} \\
\text { NAD }\end{array}$ & - & $\begin{array}{l}1 \mathrm{ml} 1 \mathrm{M} \text { sodium } \\
\text { malate }\end{array}$ & - & $\begin{array}{l}\text { MTT } \\
\text { PMS } \\
\text { Agar }\end{array}$ & $\begin{array}{r}6 \mathrm{mg} \\
2 \mathrm{mg} \\
1 \% 10 \mathrm{ml}\end{array}$ \\
\hline $\begin{array}{l}\text { ME } \\
1.1 .1 .40\end{array}$ & b & 10 & 90 & $4 \mathrm{ml} \mathrm{pH} 7.4$ & 5 & $\begin{array}{l}4 \mathrm{mg} \\
\text { NADP }\end{array}$ & - & $\begin{array}{l}1 \mathrm{ml} 1 \mathrm{M} \text { sodium } \\
\text { malate }\end{array}$ & $\begin{array}{l}40 \mathrm{mg} \\
\mathrm{MgCl} 2\end{array}$ & $\begin{array}{l}\text { MTT } \\
\text { PMS } \\
\text { Agar }\end{array}$ & $\begin{array}{r}6 \mathrm{mg} \\
2 \mathrm{mg} \\
1 \% 10 \mathrm{ml}\end{array}$ \\
\hline $\begin{array}{l}\text { IDH } \\
1.1 .1 .42\end{array}$ & b & 10 & 90 & $4 \mathrm{ml} \mathrm{pH} 8.0$ & 6 & $\begin{array}{l}4 \mathrm{mg} \\
\text { NADP }\end{array}$ & - & $\begin{array}{l}40 \mathrm{mg} \text { sodium } \\
\text { isocitrate }\end{array}$ & $\begin{array}{l}40 \mathrm{mg} \\
\mathrm{MgCl} 2\end{array}$ & $\begin{array}{l}\text { MTT } \\
\text { PMS } \\
\text { Agar }\end{array}$ & $\begin{array}{r}6 \mathrm{mg} \\
2 \mathrm{mg} \\
1 \% 10 \mathrm{ml}\end{array}$ \\
\hline $\begin{array}{l}\text { PGM } \\
1.4 .1 .9\end{array}$ & a & 20 & 60 & $4 \mathrm{ml} \mathrm{pH} 7.4$ & 6 & $\begin{array}{l}4 \mathrm{mg} \\
\text { NADP }\end{array}$ & $\begin{array}{l}2 \mathrm{U} \text { G6PDH } \\
1.1 .1 .49\end{array}$ & $\begin{array}{l}40 \mathrm{mg} \text { glucose } \\
\text { 1-phosphate }\end{array}$ & $\begin{array}{l}40 \mathrm{mg} \\
\mathrm{MgCl}\end{array}$ & $\begin{array}{l}\text { MTT } \\
\text { PMS } \\
\text { Agar }\end{array}$ & $\begin{array}{r}6 \mathrm{mg} \\
2 \mathrm{mg} \\
1 \% 10 \mathrm{ml}\end{array}$ \\
\hline $\begin{array}{l}\text { HK } \\
2.7 .1 .1\end{array}$ & c & 15 & 60 & $4 \mathrm{ml} \mathrm{pH} 7.4$ & 6 & $\begin{array}{l}4 \mathrm{mg} \\
\text { NADP }\end{array}$ & $\begin{array}{l}2 \mathrm{U} \text { G6PDH } \\
1.1 .1 .49\end{array}$ & $\begin{array}{l}100 \mathrm{mg} \\
\text { glucose }\end{array}$ & $\begin{array}{l}40 \mathrm{mg} \\
\mathrm{MgCl}\end{array}$ & $\begin{array}{l}\text { MTT } \\
\text { PMS } \\
\text { Agar }\end{array}$ & $\begin{array}{r}6 \mathrm{mg} \\
2 \mathrm{mg} \\
1 \% 10 \mathrm{ml}\end{array}$ \\
\hline $\begin{array}{l}\text { PEP 2 } \\
3.4 .11\end{array}$ & $\mathrm{c}$ & 15 & 60 & $4 \mathrm{ml} \mathrm{pH} 7.4$ & 6 & - & $\begin{array}{l}\text { 1 U L-amino } \\
\text { oxidase } \\
1.4 .3 .2 \\
\text { 2U Peroxidase } \\
1.11 .1 .7\end{array}$ & $\begin{array}{l}10 \mathrm{mg} \text { leucyl } \\
\text { glycyl- } \\
\text { glycine }\end{array}$ & $\begin{array}{l}20 \mathrm{mg} \\
\mathrm{MnCl}\end{array}$ & $\begin{array}{l}\text { 3-amin } \\
\text { carbaz } \\
\text { ethano } \\
\text { Agar }\end{array}$ & $\begin{array}{l}\text { no-9-thyl } \\
\text { zole } 10 \mathrm{mg} \\
\text { ol } 1 \mathrm{mg} \\
1 \% 10 \mathrm{ml}\end{array}$ \\
\hline $\begin{array}{l}\text { PEP.D } \\
3.4 .13 .9\end{array}$ & $\mathrm{c}$ & 15 & 60 & $4 \mathrm{ml} \mathrm{pH} 7.4$ & 6 & - & $\begin{array}{l}\text { as PEP } 2 \\
\text { with 4U } \\
\text { Peroxidase }\end{array}$ & $\begin{array}{l}10 \mathrm{ml} \\
\text { L-leucyl- } \\
\text { proline }\end{array}$ & $\begin{array}{l}20 \mathrm{mg} \\
\mathrm{MnCl} 2\end{array}$ & as PEP & 2 \\
\hline $\begin{array}{l}\text { FUM } \\
4.2 .12\end{array}$ & c & 15 & 60 & $4 \mathrm{ml} \mathrm{pH} 7.4$ & 6 & $\begin{array}{l}8 \mathrm{mg} \\
\mathrm{NAD}\end{array}$ & $\begin{array}{l}\text { 6U malate } \\
\text { dehydrogenase } \\
1.1 .1 .37\end{array}$ & $\begin{array}{l}250 \mathrm{mg} \\
\text { fumaric acid }\end{array}$ & - & $\begin{array}{l}\text { MTT } \\
\text { PMS } \\
\text { Agar }\end{array}$ & $\begin{array}{r}6 \mathrm{mg} \\
2 \mathrm{mg} \\
1 \% 10 \mathrm{ml}\end{array}$ \\
\hline $\begin{array}{l}\text { GPI } \\
5.3 .1 .9\end{array}$ & b & 10 & 90 & $4 \mathrm{ml} \mathrm{pH} 8.0$ & 6 & $\begin{array}{l}4 \mathrm{mg} \\
\text { NADP }\end{array}$ & $\begin{array}{l}\text { 2U G6PDH } \\
1.1 .1 .49\end{array}$ & $\begin{array}{l}20 \text { mg Fructose } \\
\text { 6-phosphate }\end{array}$ & $\begin{array}{l}40 \mathrm{mg} \\
\mathrm{MgCl}\end{array}$ & $\begin{array}{l}\text { MTT } \\
\text { PMS } \\
\text { Agar }\end{array}$ & $\begin{array}{r}6 \mathrm{mg} \\
2 \mathrm{mg} \\
1 \% 10 \mathrm{ml}\end{array}$ \\
\hline $\begin{array}{l}\text { MPI } \\
5.3 .1 .8\end{array}$ & b & 10 & 90 & $4 \mathrm{ml} \mathrm{pH} 7.4$ & 6 & $\begin{array}{l}4 \mathrm{mg} \\
\text { NADP }\end{array}$ & $\begin{array}{l}\text { 4U G6PDH } \\
20 \text { U GPI }\end{array}$ & $\begin{array}{l}20 \text { mg mannose } \\
6 \text {-phosphate }\end{array}$ & $\begin{array}{l}20 \mathrm{mg} \\
\mathrm{MgCl} 2\end{array}$ & $\begin{array}{l}\text { MTT } \\
\text { PMS } \\
\text { Agar }\end{array}$ & $\begin{array}{r}6 \mathrm{mg} \\
2 \mathrm{mg} \\
1 \% 10 \mathrm{ml}\end{array}$ \\
\hline
\end{tabular}

All reagents are from SIGMA Chemical Company

TABLE III

Feeding preferences of females (\%) of Anopheles albitarsis and Anopheles deaneorum (Guajará-Mirim and Rio Branco) caught in animal and human baits and indoors in 10 localities

\begin{tabular}{lcccccccccc}
\hline $\begin{array}{c}\text { Populations/ } \\
\text { Type of capture }\end{array}$ & Baradero & $\begin{array}{c}\text { São } \\
\text { Borja }\end{array}$ & $\begin{array}{c}\text { Angra } \\
\text { dos Reis }\end{array}$ & Itaguaí & $\begin{array}{c}\text { Guajará- } \\
\text { Mirim }\end{array}$ & $\begin{array}{c}\text { Rio } \\
\text { Branco }\end{array}$ & Itaituba & Paraipaba & Marajó & $\begin{array}{c}\text { Boa } \\
\text { Vista }\end{array}$ \\
\hline Animal & 100 & 52 & 80 & 88 & 30 & 35 & 74 & 53 & 23 & 32 \\
Human & - & 42 & 19 & 2 & 32 & 48 & 17 & 31 & 27 & 41 \\
Dwelling & - & 6 & - & 10 & 38 & 17 & 9 & 16 & 50 & 27 \\
\hline
\end{tabular}


TABLE IV

Costa wing banding patterns of Anopheles albitarsis and Anopheles deaneorum (Guajará-Mirim and Rio Branco) populations (A-animal, H-human and D-dwelling)

\begin{tabular}{|c|c|c|c|c|c|c|c|c|c|c|c|}
\hline $\begin{array}{c}\text { Spots/ } \\
\text { Populations } \\
\text { (specimens) }\end{array}$ & $\begin{array}{l}\text { Basal } \\
\text { dark }\end{array}$ & $\begin{array}{l}\text { Prehumeral } \\
\text { dark }\end{array}$ & $\begin{array}{l}\text { Humeral } \\
\text { dark }\end{array}$ & $\begin{array}{l}\text { Presector } \\
\text { dark }\end{array}$ & $\begin{array}{c}\text { Subbasal } \\
\text { dark }\end{array}$ & $\begin{array}{l}\text { Humeral, } \\
\text { presector } \\
\text { and median } \\
\text { fused }\end{array}$ & $\begin{array}{c}\text { Small } \\
\text { presector } \\
\text { and sector } \\
\text { pale }\end{array}$ & $\begin{array}{c}\text { Median } \\
\text { dark }\end{array}$ & $\begin{array}{c}\text { Preapical } \\
\text { dark }\end{array}$ & $\begin{array}{l}\text { Figure } \\
2\end{array}$ & Total \\
\hline Baradero & $\begin{array}{l}\text { A H D } \\
--- \\
--- \\
--- \\
3-- \\
2--\end{array}$ & $\begin{array}{c}\text { A H D } \\
15-- \\
7-- \\
\overline{3--} \\
2-- \\
2--\end{array}$ & $\begin{array}{l}\text { AH D } \\
--- \\
--- \\
--- \\
--- \\
---\end{array}$ & $\begin{array}{l}\text { A H D } \\
--- \\
--- \\
--- \\
--- \\
---\end{array}$ & $\begin{array}{c}\text { A H D } \\
15-- \\
--- \\
3-- \\
3-- \\
---\end{array}$ & $\begin{array}{l}\text { A H D } \\
--- \\
7-- \\
--- \\
\overline{2--}\end{array}$ & $\begin{array}{l}\text { A H D } \\
2-- \\
--- \\
--- \\
3-- \\
---\end{array}$ & $\begin{array}{c}\text { A H D } \\
15-- \\
--- \\
3-- \\
3-- \\
---\end{array}$ & $\begin{array}{c}\text { A H D } \\
15-- \\
7-- \\
3-- \\
3-- \\
2--\end{array}$ & $\begin{array}{l}b \\
d \\
f \\
a \\
g\end{array}$ & $\begin{array}{r}15 \\
7 \\
3 \\
3 \\
2\end{array}$ \\
\hline $\begin{array}{l}\text { São } \\
\text { Borja } \\
(25)\end{array}$ & $\begin{array}{l}--- \\
--\overline{-} \\
-11 \\
--- \\
--\overline{-} \\
--1\end{array}$ & $\begin{array}{l}65- \\
5521 \\
-11 \\
--\overline{1} \\
-1- \\
---\end{array}$ & $\begin{array}{l}--- \\
--- \\
--- \\
--- \\
--- \\
---\end{array}$ & $\begin{array}{l}--- \\
--- \\
--- \\
--- \\
--- \\
---\end{array}$ & 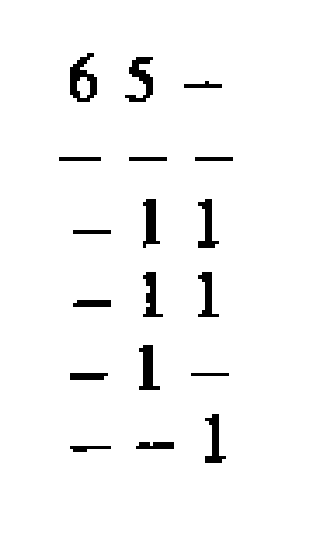 & $\begin{array}{l}-\overline{5}-\overline{ } \\
--- \\
--- \\
--- \\
---\end{array}$ & $\begin{array}{l}-4- \\
-\overline{1}- \\
-11 \\
--- \\
--\overline{-} \\
--1\end{array}$ & $\begin{array}{l}65- \\
-\overline{-1} \\
-11 \\
-11 \\
-1- \\
--1\end{array}$ & $\begin{array}{lll}6 & 5 & - \\
5 & 2 & 1 \\
-1 & 1 \\
-1 & 1 \\
-1 & -1 \\
- & - & -1\end{array}$ & $\begin{array}{l}b^{a} \\
d \\
a \\
f \\
b \\
h\end{array}$ & $\begin{array}{r}11 \\
8 \\
2 \\
2 \\
1 \\
1\end{array}$ \\
\hline $\begin{array}{l}\text { Angra } \\
\text { dos } \\
\text { Reis } \\
(16)\end{array}$ & $\begin{array}{l}53- \\
33- \\
--- \\
---\end{array}$ & $\begin{array}{l}53- \\
33- \\
1-- \\
1--\end{array}$ & $\begin{array}{l}-\overline{-}- \\
33- \\
\overline{1}-- \\
1--\end{array}$ & $\begin{array}{l}-\overline{-}- \\
33- \\
-1-- \\
1--\end{array}$ & $\begin{array}{l}53- \\
--- \\
1-- \\
---\end{array}$ & $\begin{array}{l}--- \\
--- \\
--- \\
---\end{array}$ & $\begin{array}{l}--- \\
--- \\
--- \\
---\end{array}$ & $\begin{array}{l}53- \\
33- \\
1-- \\
1--\end{array}$ & $\begin{array}{l}53- \\
33- \\
1-- \\
1--\end{array}$ & $\begin{array}{l}a \\
c \\
b \\
e\end{array}$ & $\begin{array}{l}8 \\
6 \\
1 \\
1\end{array}$ \\
\hline $\begin{array}{l}\text { ltaguar } \\
(30)\end{array}$ & $\begin{array}{l}1352 \\
--- \\
2-- \\
--- \\
---\end{array}$ & $\begin{array}{c}1352 \\
141 \\
2-- \\
-1- \\
1^{\mathrm{a}}--\end{array}$ & $\begin{array}{l}--- \\
\overline{-}-- \\
2-- \\
-1- \\
---\end{array}$ & $\begin{array}{l}--- \\
\overline{-}- \\
2-- \\
-1- \\
---\end{array}$ & $\begin{array}{c}1352 \\
141 \\
--- \\
--- \\
1--\end{array}$ & $\begin{array}{l}--- \\
--- \\
--- \\
--- \\
---\end{array}$ & $\begin{array}{l}--- \\
\overline{-}- \\
2-- \\
--- \\
---\end{array}$ & $\begin{array}{l}1352 \\
141 \\
2-- \\
-1- \\
1--\end{array}$ & $\begin{array}{l}1352 \\
141 \\
2-- \\
-1- \\
1--\end{array}$ & $\begin{array}{l}\mathrm{a} \\
\mathrm{b} \\
\mathrm{c} \\
\mathrm{e} \\
\mathrm{b}^{\mathrm{a}}\end{array}$ & $\begin{array}{r}20 \\
6 \\
2 \\
1 \\
1\end{array}$ \\
\hline $\begin{array}{l}\text { Guajará- } \\
\text { Mirim } \\
\text { (30) }\end{array}$ & $\begin{array}{c}36- \\
--- \\
\overline{-}-- \\
11 \\
--- \\
1^{\mathrm{a}}-- \\
1^{\mathrm{a}}-- \\
-1- \\
---\end{array}$ & $\begin{array}{l}36- \\
4-5 \\
-23 \\
-11 \\
--- \\
1-- \\
1^{a}-- \\
--\overline{-} \\
--1\end{array}$ & $\begin{array}{l}--- \\
--\overline{-} \\
-23 \\
-11 \\
--- \\
--- \\
--- \\
--- \\
---\end{array}$ & $\begin{array}{l}--- \\
--\overline{-} \\
-23 \\
-11 \\
---- \\
--- \\
--- \\
--- \\
---\end{array}$ & $\begin{array}{l}36- \\
4-5 \\
--- \\
--- \\
1-- \\
1-- \\
1-- \\
-1- \\
---\end{array}$ & $\begin{array}{l}--- \\
--- \\
--- \\
--- \\
--- \\
--- \\
--- \\
---\overline{-} \\
--1\end{array}$ & $\begin{array}{l}--- \\
--- \\
--- \\
--- \\
--- \\
--- \\
--- \\
--- \\
---\end{array}$ & $\begin{array}{l}36- \\
4-5 \\
-23 \\
-11 \\
1-- \\
1-- \\
1-- \\
-1- \\
---\end{array}$ & $\begin{array}{l}36- \\
4-5 \\
-23 \\
-11 \\
1-- \\
1-- \\
1-- \\
-1- \\
--1\end{array}$ & $\begin{array}{l}\mathrm{a} \\
\mathrm{b} \\
\mathrm{e} \\
\mathrm{c} \\
\mathrm{f} \\
\mathrm{a}^{\mathrm{a}} \\
\mathrm{a}^{\mathrm{a}} \\
\mathrm{h} \\
\mathrm{d}\end{array}$ & $\begin{array}{l}9 \\
9 \\
5 \\
2 \\
1 \\
1 \\
1 \\
1 \\
1\end{array}$ \\
\hline $\begin{array}{l}\text { Rio } \\
\text { Branco } \\
(30)\end{array}$ & $\begin{array}{l}-\overline{5} \overline{-} \\
--- \\
--- \\
-1^{\mathrm{a}}-\end{array}$ & $\begin{array}{lll}4 & 5 & 7 \\
5 & 2 & 2 \\
- & 2 & 1 \\
- & - & - \\
- & -1 & -\end{array}$ & $\begin{array}{l}--- \\
-\overline{2} \\
-21 \\
--- \\
---\end{array}$ & $\begin{array}{l}--- \\
--\overline{2} \\
-21 \\
--- \\
---\end{array}$ & $\begin{array}{l}4557 \\
522 \\
---- \\
1-- \\
-1-\end{array}$ & $\begin{array}{l}--- \\
--- \\
--- \\
--- \\
---\end{array}$ & $\begin{array}{l}--- \\
--- \\
--- \\
--- \\
---\end{array}$ & 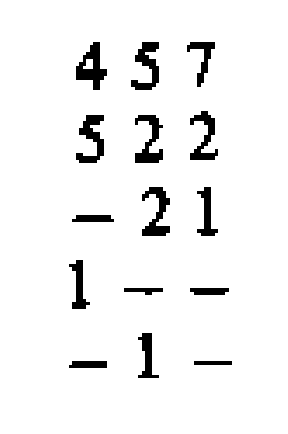 & $\begin{array}{l}457 \\
522 \\
-21 \\
1-- \\
-1-\end{array}$ & $\begin{array}{l}\mathrm{b} \\
\mathrm{a} \\
\mathrm{e} \\
\mathrm{f} \\
\mathrm{a}^{\mathrm{a}}\end{array}$ & $\begin{array}{r}16 \\
9 \\
3 \\
1 \\
1\end{array}$ \\
\hline $\begin{array}{l}\text { Itaituba } \\
(30)\end{array}$ & $\begin{array}{c}463 \\
435 \\
--- \\
1 a_{--} \\
1-- \\
---\end{array}$ & $\begin{array}{l}4633 \\
435 \\
--12 \\
1-- \\
1-1- \\
-1-\end{array}$ & $\begin{array}{l}--\overline{-} \\
435 \\
--- \\
--- \\
--- \\
-1-\end{array}$ & $\begin{array}{l}-\overline{4} \\
435 \\
--- \\
--- \\
-\overline{-1}- \\
-1-\end{array}$ & $\begin{array}{c}463 \\
---\overline{2} \\
--2 \\
1-- \\
--- \\
---\end{array}$ & $\begin{array}{l}--- \\
--- \\
--- \\
\overline{-}-- \\
1-- \\
---\end{array}$ & $\begin{array}{l}1-- \\
--- \\
--- \\
--- \\
--- \\
---\end{array}$ & $\begin{array}{c}463 \\
435 \\
--2 \\
1-- \\
--- \\
-1-\end{array}$ & $\begin{array}{l}463 \\
435 \\
--2 \\
1-- \\
1-- \\
-1-\end{array}$ & $\begin{array}{c}\mathrm{a} \\
\mathrm{c} \\
\mathrm{b} \\
\mathrm{a}^{\mathrm{a}} \\
\mathbf{g} \\
\mathrm{e}\end{array}$ & $\begin{array}{r}13 \\
12 \\
2 \\
1 \\
1 \\
1\end{array}$ \\
\hline $\begin{array}{l}\text { Paraipaba } \\
\text { (30) }\end{array}$ & $\begin{array}{l}966 \\
-44 \\
---\end{array}$ & $\begin{array}{l}966 \\
-44 \\
1--\end{array}$ & $\begin{array}{l}--\overline{4} \\
-44 \\
---\end{array}$ & $\begin{array}{l}--- \\
-44 \\
---\end{array}$ & $\begin{array}{l}966 \\
--- \\
1--\end{array}$ & $\begin{array}{l}--- \\
--- \\
---\end{array}$ & $\begin{array}{l}--- \\
--- \\
---\end{array}$ & $\begin{array}{l}966 \\
-44 \\
1--\end{array}$ & $\begin{array}{l}966 \\
-44 \\
1--\end{array}$ & $\begin{array}{l}a \\
c \\
b\end{array}$ & $\begin{array}{r}21 \\
8 \\
1\end{array}$ \\
\hline $\begin{array}{l}\text { Marajó } \\
(30)\end{array}$ & $\begin{array}{l}666 \\
122 \\
---- \\
---\overline{1} \\
--1 \\
--1^{a}\end{array}$ & $\begin{array}{lll}6 & 6 & 6 \\
1 & 2 & 2 \\
2 & 2 & - \\
1 & - & - \\
- & -1 \\
- & -1\end{array}$ & $\begin{array}{l}-\overline{12} \\
--- \\
1-- \\
---- \\
---\end{array}$ & $\begin{array}{l}-\overline{1} \overline{2} \\
--- \\
1-- \\
--- \\
---\end{array}$ & $\begin{array}{l}666 \\
\overline{2} 2-- \\
--- \\
--\overline{-} \\
--1\end{array}$ & $\begin{array}{l}--- \\
--- \\
--- \\
--- \\
--1 \\
---\end{array}$ & $\begin{array}{l}--- \\
--- \\
--- \\
--- \\
--- \\
--1\end{array}$ & 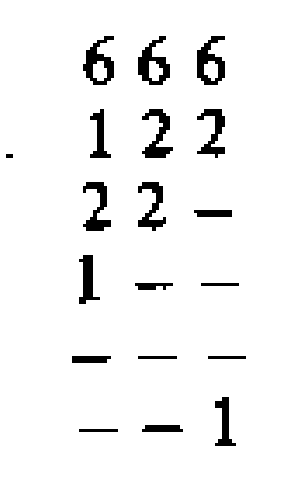 & 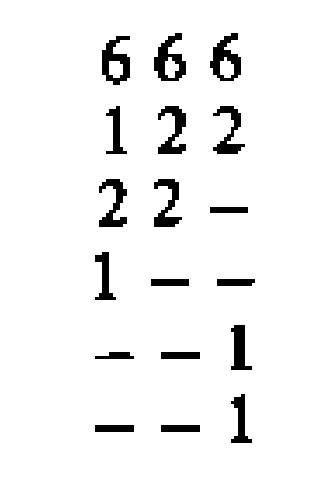 & $\begin{array}{c}\mathrm{a} \\
\mathrm{c} \\
\mathrm{b} \\
\mathrm{e} \\
\mathrm{g} \\
\mathrm{a}^{\mathbf{a}}\end{array}$ & $\begin{array}{r}18 \\
5 \\
4 \\
1 \\
1 \\
1\end{array}$ \\
\hline $\begin{array}{l}\text { Boa Vista } \\
(30)\end{array}$ & $\begin{array}{l}999 \\
-11 \\
---\end{array}$ & $\begin{array}{l}999 \\
-11 \\
1--\end{array}$ & $\begin{array}{l}-\overline{-} \\
-11 \\
---\end{array}$ & $\begin{array}{l}-\overline{-} \\
-11 \\
---\end{array}$ & $\begin{array}{l}999 \\
\frac{1--}{1--}\end{array}$ & $\begin{array}{l}--- \\
--- \\
---\end{array}$ & $\begin{array}{l}--- \\
--- \\
---\end{array}$ & $\begin{array}{l}999 \\
-11 \\
1--\end{array}$ & $\begin{array}{l}999 \\
-11 \\
1--\end{array}$ & $\begin{array}{l}\mathbf{a} \\
\mathbf{c} \\
\mathbf{b}\end{array}$ & $\begin{array}{r}27 \\
2 \\
1\end{array}$ \\
\hline & 178 & 272 & 49 & 49 & 212 & 20 & 16 & 261 & 281 & & 281 \\
\hline
\end{tabular}

a very small spots. 
TABLE $\mathrm{V}$

Banding pattern of veins 1, 2,4 and 5 of the wings in 221 specimens of Anopheles albitarsis and 60 of Anopheles deaneorum (Guajará-Mirim and Rio Branco) (A-anima), H-human and Ddwelling)

\begin{tabular}{|c|c|c|c|c|c|c|c|c|c|c|c|c|c|c|c|c|c|c|c|c|c|c|c|c|c|}
\hline \multirow{2}{*}{$\begin{array}{c}\text { Vein } \\
\text { No. spots/ } \\
\text { Populations } \\
\text { (specimens) }\end{array}$} & \multicolumn{4}{|c|}{$\mathbf{R}_{1}$} & \multicolumn{6}{|c|}{$R_{2}$ and $R_{2}+3$} & \multicolumn{4}{|c|}{$\mathbf{R}_{\mathbf{3}}$} & \multicolumn{5}{|c|}{$M_{1}$} & \multicolumn{2}{|c|}{$\mathrm{M}_{2}$} & \multicolumn{4}{|c|}{$\mathrm{CuA}$ and $\mathrm{M}_{3}+4$} \\
\hline & 3 & 4 & 5 & 6 & 2 & 3 & 4 & $s$ & 6 & 7 & 0 & 1 & 2 & 3 & 2 & 3 & 4 & 5 & 6 & 1 & 2 & 4 & 3 & 2 & $3^{\mathrm{a}}$ \\
\hline $\begin{array}{l}\text { Baradero } \\
\text { (30) }\end{array}$ & $\begin{array}{l}\text { A H D } \\
---\end{array}$ & $\begin{array}{c}\text { A H D } \\
3--2\end{array}$ & $\begin{array}{l}\text { A H D } \\
27--\end{array}$ & $\begin{array}{c}\text { A H D } \\
---\end{array}$ & $\begin{array}{l}\text { A H D } \\
---\end{array}$ & $\begin{array}{c}\text { A H D } \\
7--\end{array}$ & $\begin{array}{l}\text { A H D } \\
9_{--}\end{array}$ & $\begin{array}{l}\text { A H D } \\
4--\end{array}$ & $\begin{array}{l}\text { AH D } \\
3--\end{array}$ & $\begin{array}{l}\text { A H D } \\
1--\end{array}$ & $\begin{array}{l}\text { A H D } \\
---\end{array}$ & $\begin{array}{c}\text { A H D } \\
\mathbf{3}--\end{array}$ & $\begin{array}{l}\text { A H D } \\
21--\end{array}$ & $\begin{array}{c}\text { A H D } \\
---\end{array}$ & $\begin{array}{c}\text { A H D } \\
\text { S- - }\end{array}$ & $\begin{array}{l}\text { A H D } \\
11--\end{array}$ & $\begin{array}{l}\text { A H D } \\
5--\end{array}$ & $\begin{array}{c}\text { A H D } \\
3--\end{array}$ & $\begin{array}{l}\text { A H D } \\
---\end{array}$ & $\begin{array}{l}\text { A H D } \\
24--\end{array}$ & $\begin{array}{l}\text { A H D } \\
---\end{array}$ & $\begin{array}{l}\text { A H D } \\
17--\end{array}$ & $\begin{array}{l}\text { A H D } \\
11--\end{array}$ & $\begin{array}{l}\text { A H D } \\
1--\end{array}$ & $\begin{array}{l}\text { A H D } \\
1--\end{array}$ \\
\hline $\begin{array}{l}\text { Sāo Borja } \\
(25)\end{array}$ & --- & 211 & 983 & --1 & --- & $1--$ & $21-$ & 255 & $54-$ & $-\cdots$ & -- & --1 & 1094 & $-1-$ & --- & $54-$ & $55-$ & $-1-$ & --- & $109-$ & $-1-$ & 753 & 232 & $-1-$ & $11-$ \\
\hline Itaguaí & --- & $3-1$ & 14102 & --- & --- & $2--$ & $24-$ & 422 & 941 & --- & $1--$ & $1--$ & 15103 & --- & --- & 411 & 632 & $56-$ & $2--$ & 1793 & $-1-$ & 15103 & --- & --- & --- \\
\hline $\begin{array}{l}\text { Angra dos } \\
\text { Reis (16) }\end{array}$ & --- & $15-$ & $91-$ & --- & --- & --- & $-1-$ & $22-$ & $83-$ & --- & --- & $31-$ & $75-$ & --- & --- & $-2-$ & $104-$ & $-2-$ & $-3-$ & $75-$ & $31 .-$ & $72-$ & $34-$ & --- & --- \\
\hline $\begin{array}{l}\text { Guajará- } \\
\text { Mirim (30) }\end{array}$ & -24 & 363 & 723 & r - - & $1-2$ & --2 & 232 & 421 & 242 & $1--$ & $1-1$ & 653 & 356 & --- & -13 & 745 & 222 & $12-$ & $-1-$ & 1098 & -22 & 544 & 134 & $4--$ & -32 \\
\hline $\begin{array}{l}\text { Rio Branco } \\
\text { (30) }\end{array}$ & 646 & 363 & $1-1$ & --- & -12 & 212 & 262 & 511 & -13 & --- & $-2-$ & 112 & 977 & $1-1$ & -22 & 363 & 424 & $1-1$ & $2--$ & 5109 & $5-1$ & 255 & 835 & $-1-$ & --1 \\
\hline $\begin{array}{l}\text { ltaituba } \\
\text { (30) }\end{array}$ & --- & 511 & 499 & $1--$ & $1-1$ & --1 & 241 & 746 & --2 & --1 & --- & 351 & 758 & $-\cdots$ & --2 & 356 & 741 & -11 & --- & 101010 & --- & $4-3$ & 575 & 231 & --1 \\
\hline $\begin{array}{l}\text { Paraipaba } \\
\text { (30) }\end{array}$ & --- & $-1-$ & 989 & --- & --- & --- & -11 & 414 & 585 & $1--$ & --- & --- & 101010 & --- & $-1-$ & 532 & 367 & $2-1$ & ---1 & 101010 & --- & 977 & 133 & --- & --- \\
\hline $\begin{array}{l}\text { Marajó } \\
(30)\end{array}$ & --- & 323 & 686 & $1--$ & $1--$ & -11 & -24 & 663 & 312 & --- & $2--$ & 577 & 333 & --- & 413 & 485 & 212 & --- & --- & 101010 & --- & 668 & 442 & --- & --- \\
\hline $\begin{array}{l}\text { Boa Vista } \\
(30)\end{array}$ & --- & --- & 101010 & --- & $31-$ & --- & 314 & 275 & 211 & --- & $1--$ & $2--$ & 7107 & --3 & $2--$ & 452 & 235 & 113 & $-1-$ & 934 & 176 & 395 & 515 & $1--$ & --- \\
\hline Total (281) & 22 & 57 & 195 & 3 & 13 & 20 & 59 & 97 & 79 & 4 & 8 & 57 & 204 & 6 & 26 & 108 & 99 & 32 & 9 & 241 & 30 & 161 & 94 & 14 & 10 \\
\hline
\end{tabular}

$3^{\mathrm{a}}$ refers to the first spot in $\mathrm{M} 3+4$ being close to that of CuA, while 3 is the farther. 

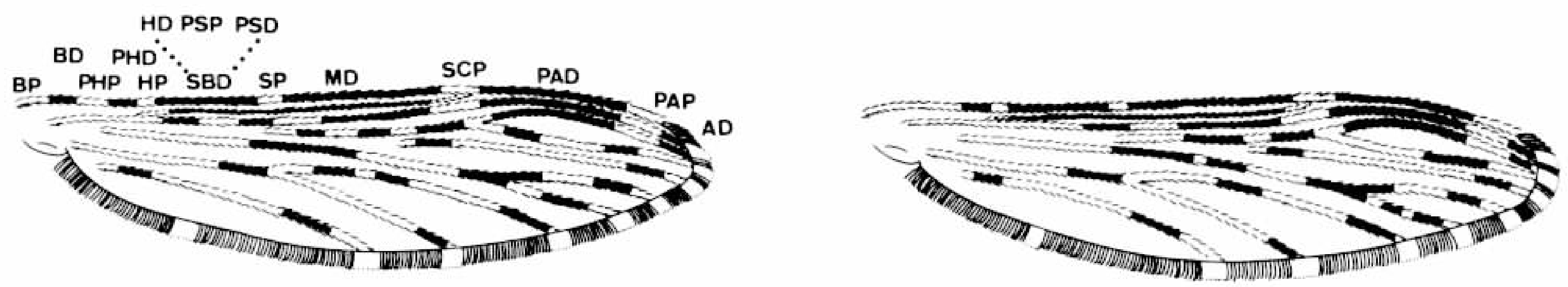

a
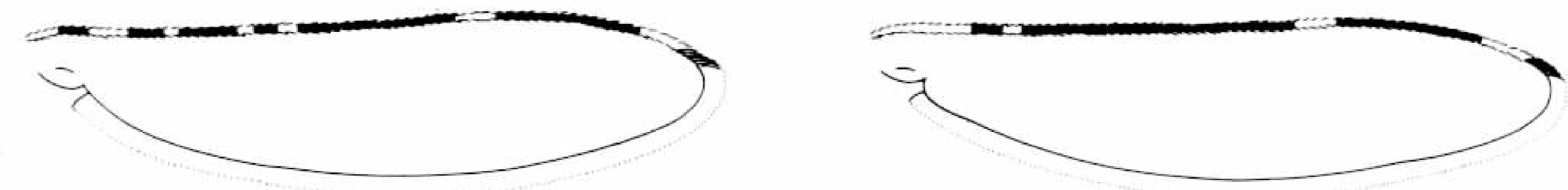

C
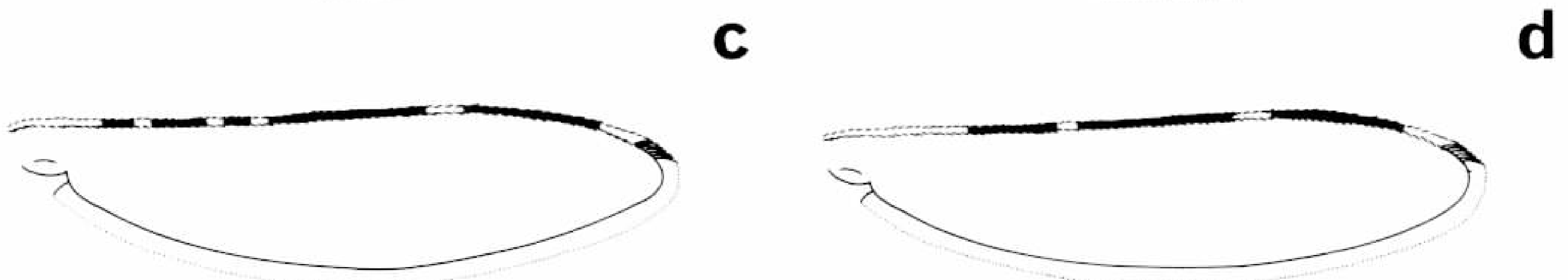

e
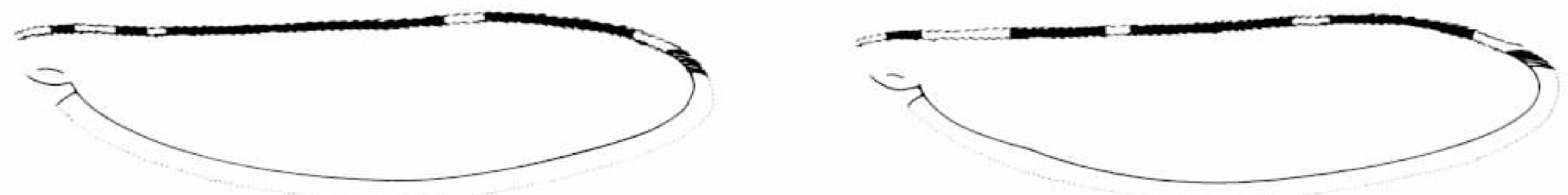

g

Fig. 2: types of costa wing banding patterns of Anopheles albitarsis and Anopheles deaneorum populations. Types were lettered from a to $\mathrm{h}$ according frequency. Types a and $\mathrm{b}$, which contribute with $48 \%$ and $24.2 \%$ respectively also show the 2 most frequent banding patterns of other veins (PHP, PHD - prehumeral pale and dark; HP, HD - humeral pale and dark; PSP, PSD - presector pale and dark; SBD - subbasal dark; SP - sector pale; MD - median dark; SCP - subcostal pale; PAD, PAP - preapical dark and pale; AD - apical dark).

There was no variation in shape or number of setae and scales from head, occiput, vertex and antenna. The same was observed for setae and scales of the pleurotergites, scutum and scutellum. Abdominal tufts of black scales were differently inserted among populations. They appear only in the 4 th or 5 th segment in Guajará-Mirim and Rio Branco, while in the 3rd for all others. Some specimens had 1 or 2 scales in the 2nd tergite that can not be considered a true tuft. Specimens from all 10 populations had the doubled row of scales in the 1st sternite, $\mathrm{U}$ or $\mathrm{V}$-shaped, a characteristic only present in albitarsis, deaneorum and braziliensis that distinguishes them from other species of the argyritarsis series. In 9 male and 9 female genitalias and cibarial armatures mounted for each locality no difference was found.
Wing spots were counted for costa (Table IV) and for every vein (Table V). There are 8 wing costa banding patterns with some patterns being more frequent in some populations. Black spots in veins 1 to 6 were also variable (Fig. 2). For costa wing spots, samples A (animal), H (human) and D (dwelling) were very homogeneous in every population. Types $a$ and $b$ from Fig. 2 were the most frequent and were present in all populations.

The distribution of wing costa types were as follows in the 281 specimens studied: type a, $48 \%$ of the total with 135 specimens; type b, $24.2 \%$ (68 specimens); type c, $13.2 \%$ (37); type d, $5.7 \%$ (16); type e, $4.3 \%$ (12); type f, $2.5 \%$ (7); type g, $1.4 \%$ (4) and type h, 0.7\% (2). All in all the 8 types can be divided in 3 sub- 
groups, varying for having or not the 2 first dark spots: the basal and prehumeral. The first group composed by a, b, f and $h$, had a with both basal and prehumeral spots, b only with prehumeral, $h$ only basal and $f$ none of them. The second group, formed by $\mathrm{c}$ and $\mathrm{e}$, has $\mathrm{c}$ with the 2 spots and e without basal. The third group with $\mathrm{d}$ and $\mathrm{g}$, has $\mathrm{g}$ with the 2 spots and $\mathrm{d}$ without basal.

Spots in the 6 veins were also counted in 281 specimens. Veins 3 and 6 as in all Nyssorhynchus subgenus present 1 spot near distal and proximal extremities respectively. Other veins (1, 2, 4 and 5) with variable number of dark spots. Results are showed in Table V.

No difference was noted in the legs of the mosquitoes in the different populations except for the variable percentage of dark scales in the 2 nd hindtarsomere (Table VI). Nine hundred and eighteen specimens were analyzed for this character and several correlations were evaluated through Spearman's coefficient, Student's t and Kruskal-Wallis tests as influence of latitude and behaviour (endophily, anthropophily and zoophily) on black extension of 2 nd hindtarsomere (Figs 3, 4, 5).

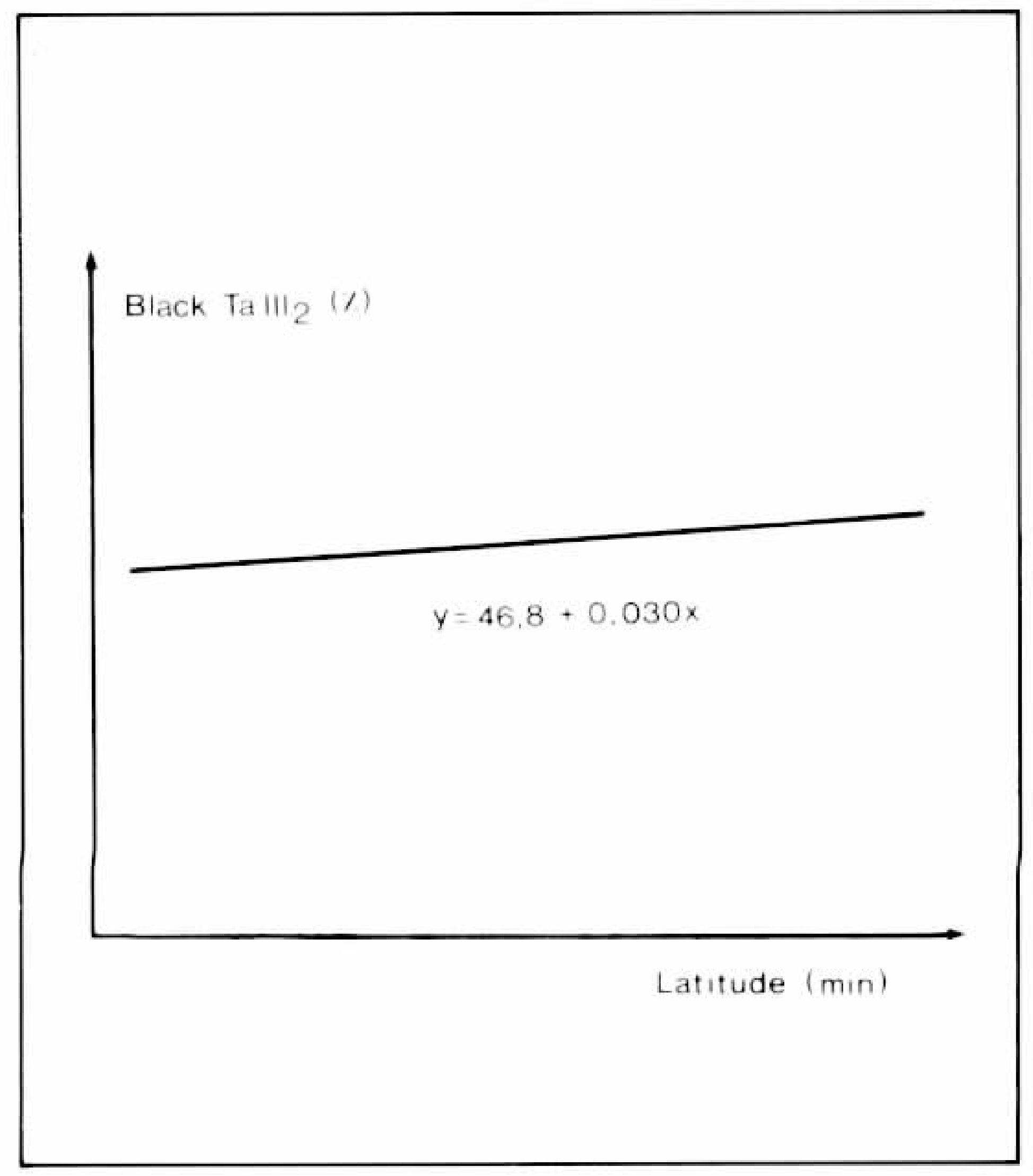

Fig. 3: comparison of the average of percentage of black in the 2 nd hindtarsomere to latitude (in $\mathrm{min}$ ) of 8 populations of Anopheles albitarsis.

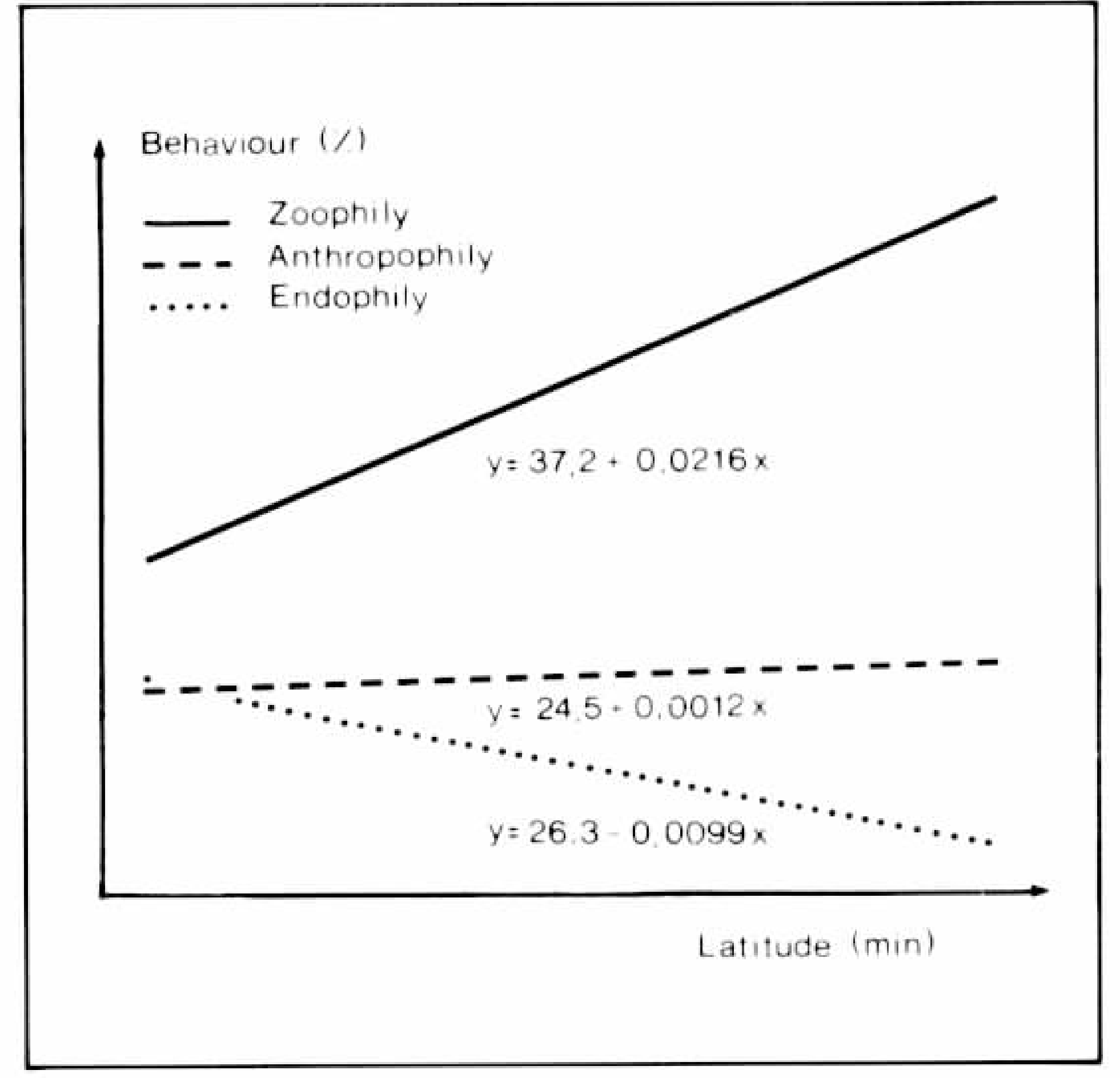

Fig. 4: comparison of feeding behaviour (zoophily, anthropophily and endophily) to latitude (in $\mathrm{min}$ ) of 8 populations of Anopheles albitarsis caught outdoors, in human and animal baits and indoors.

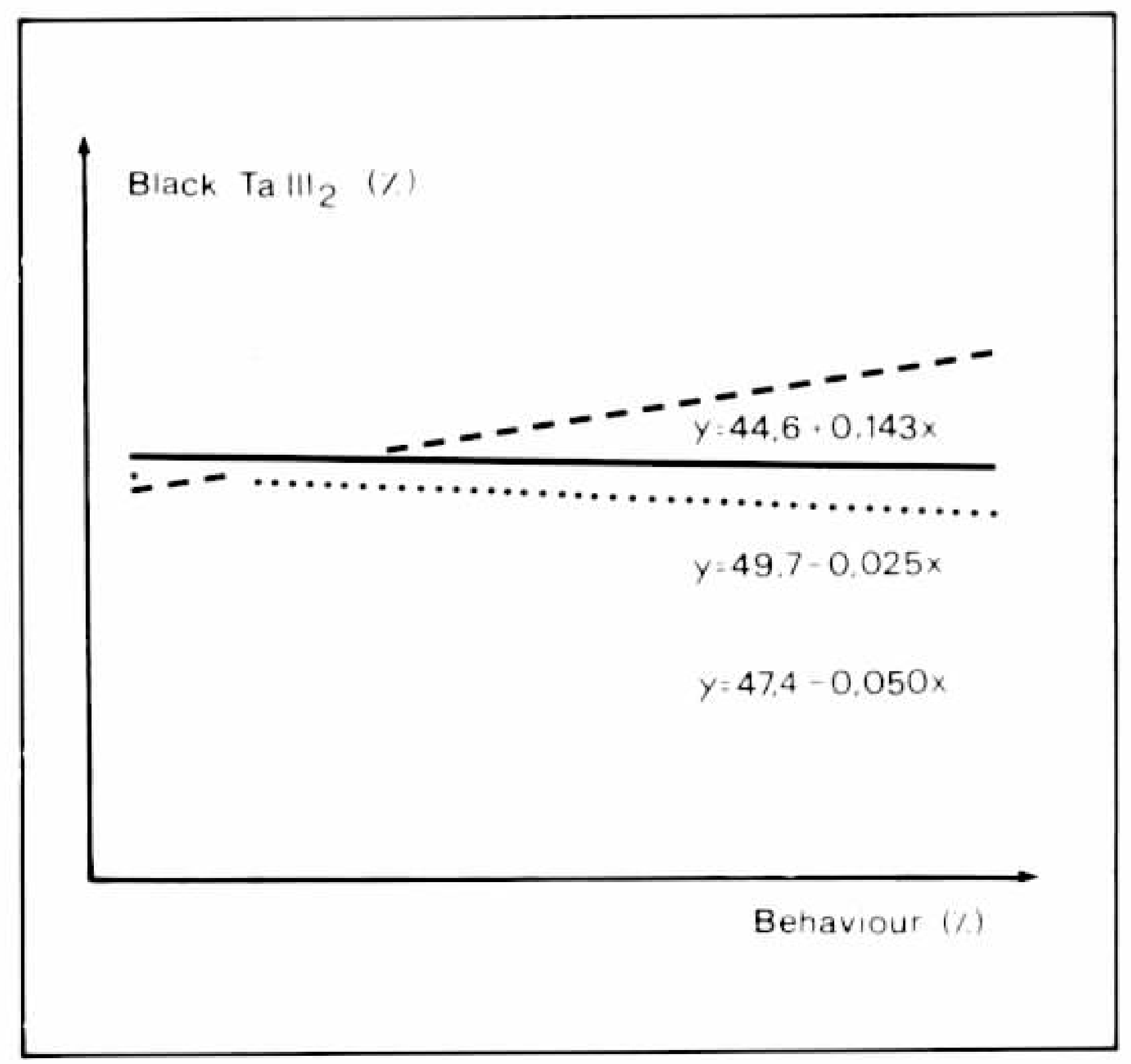

Fig. 5: comparison of percentage black in the 2nd hindtarsomere to behaviour $(\%)$ of 8 populations of Anopheles albitarsis caught outdoors, in animal and human baits, and indoors.

Statistical analysis of the results showed a significant decrease of endophily with increase in latitude (Spearman's coefficient and Student's test). Evidence for increase in zoophily and in the percentage black in the 2 nd hind tarsomere with increase in latitude was conflicting (only Spearman's coefficient approval). No other significant correlation was found. 


\section{TABLE VI}

Average, standard deviation and range of the \% black in the 2 nd hindtarsomere of female and male of Anopheles albitarsis and Anopheles deaneorum (Guajará-Mirim and Rio Branco) with latitude, longitude and type of capture

\begin{tabular}{|c|c|c|c|c|c|c|c|}
\hline $\begin{array}{l}\text { Populations } \\
\text { (specimens) }\end{array}$ & $\begin{array}{l}\text { Latitude/ } \\
\text { Longitude }\end{array}$ & $\begin{array}{l}\text { Type of } \\
\text { capture }\end{array}$ & $\begin{array}{l}\text { Specimens } \\
\text { studied } \\
\text { female }\end{array}$ & male & $\begin{array}{c}\text { Average of } \\
\% \text { black } \\
\text { TaIII-2 }\end{array}$ & $\begin{array}{l}\text { Range of } \\
\text { variation }\end{array}$ & $\begin{array}{l}\text { Standard } \\
\text { Deviation }\end{array}$ \\
\hline $\begin{array}{l}\text { Baradero } \\
(66)\end{array}$ & $\begin{array}{l}33^{\circ} 50^{\prime} \mathrm{S} \\
59^{\circ} 30^{\prime} \mathrm{W}\end{array}$ & cattle & 49 & 17 & $\begin{array}{l}62,5 \\
55,3\end{array}$ & $\begin{array}{l}50,0-80,6 \\
41,7-68,8\end{array}$ & $\begin{array}{l}6,86 \\
6,96\end{array}$ \\
\hline $\begin{array}{l}\text { São Borja } \\
(140)\end{array}$ & $\begin{array}{c}28^{\circ} 39^{\circ} 38^{\prime \prime} \mathrm{S} \\
56^{\circ} 00^{\prime} 16^{\prime \prime} \mathrm{W}\end{array}$ & $\begin{array}{l}\text { horse } \\
\text { human } \\
\text { dwelling }\end{array}$ & $\begin{array}{r}65 \\
40 \\
5\end{array}$ & $\begin{array}{l}19 \\
11 \\
-\end{array}$ & $\begin{array}{l}57,6 \\
59,6 \\
63,6 \\
61,5 \\
61,2 \\
-\end{array}$ & $\begin{array}{c}37,9-80,4 \\
50,0-82,6 \\
38,7-82,4 \\
47,6-71,0 \\
43,7-71,8 \\
-\end{array}$ & $\begin{array}{c}7,71 \\
8,17 \\
9,82 \\
7,07 \\
11,18 \\
-\end{array}$ \\
\hline $\begin{array}{l}\text { Angra dos } \\
\text { Reis } \\
(53)\end{array}$ & $\begin{array}{l}23^{\circ} 00^{\prime} 24 " \mathrm{~S} \\
44^{\circ} 19^{\prime} 05^{\prime \prime} \mathrm{W}\end{array}$ & $\begin{array}{l}\text { horse } \\
\text { human } \\
\text { dwelling }\end{array}$ & $\begin{array}{r}28 \\
3 \\
-\end{array}$ & $\begin{array}{r}19 \\
3 \\
-\end{array}$ & $\begin{array}{l}46,5 \\
47,7 \\
44,4 \\
52,6 \\
- \\
-\end{array}$ & $\begin{array}{c}37,0-54,6 \\
36,4-66,7 \\
38,5-48,2 \\
50,0-56,0 \\
- \\
-\end{array}$ & $\begin{array}{c}5,31 \\
7,47 \\
5,17 \\
3,07 \\
- \\
-\end{array}$ \\
\hline $\begin{array}{l}\text { Itaguai } \\
(69)\end{array}$ & $\begin{array}{l}22^{\circ} 51^{\prime} 08^{\prime \prime} \mathrm{S} \\
4304631^{\prime \prime W}\end{array}$ & $\begin{array}{l}\text { horse } \\
\text { human } \\
\text { dwelling }\end{array}$ & $\begin{array}{r}20 \\
6 \\
3\end{array}$ & $\begin{array}{r}34 \\
5 \\
1\end{array}$ & $\begin{array}{l}51,5 \\
52,0 \\
51,9 \\
49,0 \\
57,5 \\
51,6\end{array}$ & $\begin{array}{c}45,9-56,3 \\
34,3-64,7 \\
42,8-62,5 \\
41,7-53,8 \\
42,8-62,5 \\
\quad-\end{array}$ & $\begin{array}{l}3,20 \\
6,99 \\
7,45 \\
4,90 \\
6,61 \\
-\end{array}$ \\
\hline $\begin{array}{l}\text { Guajará- } \\
\text { Mirim } \\
(66)\end{array}$ & $\begin{array}{l}10^{\circ} 46^{\prime} 59^{\prime \prime} \mathrm{S} \\
65^{\circ} 20^{\prime} 22^{\prime \prime} \mathrm{W}\end{array}$ & $\begin{array}{l}\text { horse } \\
\text { human } \\
\text { dwelling }\end{array}$ & $\begin{array}{r}20 \\
6 \\
7\end{array}$ & $\begin{array}{r}19 \\
8 \\
6\end{array}$ & $\begin{array}{l}67,8 \\
70,2 \\
54,1 \\
64,2 \\
67,0 \\
54,5\end{array}$ & $\begin{array}{l}56,7-83,9 \\
62,1-82,1 \\
50,0-60,0 \\
54,8-72,0 \\
62,2-73,3 \\
50,0-66,7\end{array}$ & $\begin{array}{l}6,61 \\
5,86 \\
3,99 \\
6,04 \\
3,74 \\
6,59\end{array}$ \\
\hline $\begin{array}{l}\text { Rio Branco } \\
\text { (133) }\end{array}$ & $\begin{array}{l}09^{\circ} 58 ' 29 " \mathrm{~S} \\
67^{\circ} 48^{\prime} 36^{\prime \prime} \mathrm{W}\end{array}$ & $\begin{array}{l}\text { horse } \\
\text { human } \\
\text { dwelling }\end{array}$ & $\begin{array}{l}14 \\
41 \\
14\end{array}$ & $\begin{array}{l}22 \\
24 \\
18\end{array}$ & $\begin{array}{l}66,0 \\
66,7 \\
63,9 \\
62,0 \\
63,9 \\
61,3\end{array}$ & $\begin{array}{l}52,8-76,9 \\
52,0-85,0 \\
40,0-75,0 \\
53,6-68,0 \\
39,4-80,6 \\
43,3-71,4\end{array}$ & $\begin{array}{l}7,35 \\
7,78 \\
7,57 \\
4,00 \\
9,42 \\
6,66\end{array}$ \\
\hline $\begin{array}{l}\text { Itaguaí } \\
(81)\end{array}$ & $\begin{array}{l}04^{\circ} 16^{\prime} 34^{\prime \prime} \mathrm{S} \\
55^{\circ} 59^{\prime} 01^{\prime \prime}\end{array}$ & $\begin{array}{l}\text { cattle } \\
\text { human } \\
\text { dwelling }\end{array}$ & $\begin{array}{l}17 \\
11 \\
16\end{array}$ & $\begin{array}{r}9 \\
18 \\
10\end{array}$ & $\begin{array}{l}42,7 \\
38,3 \\
42,3 \\
39,6 \\
46,3 \\
41,2\end{array}$ & $\begin{array}{l}35,7-55,0 \\
33,3-47,4 \\
34,6-45,8 \\
29,6-47,6 \\
34,5-53,6 \\
20,0-47,8\end{array}$ & $\begin{array}{l}6,45 \\
4,78 \\
3,17 \\
4,44 \\
5,90 \\
7,90\end{array}$ \\
\hline $\begin{array}{l}\text { Paraipaba } \\
(84)\end{array}$ & $\begin{array}{l}03^{\circ} 26^{\prime} 22^{\prime \prime} \mathrm{S} \\
39^{\circ} 08^{\prime} 54 \mathrm{~W}\end{array}$ & $\begin{array}{l}\text { donkey } \\
\text { human } \\
\text { dwelling }\end{array}$ & $\begin{array}{l}34 \\
20 \\
15\end{array}$ & $\begin{array}{l}5 \\
5 \\
5\end{array}$ & $\begin{array}{l}36,1 \\
43,3 \\
38,5 \\
35,7 \\
39,5 \\
36,1\end{array}$ & $\begin{array}{l}25,9-48,2 \\
41,0-46,4 \\
28,0-44,0 \\
31,8-41,0 \\
32,0-56,7 \\
31,6-40,0\end{array}$ & $\begin{array}{l}5,35 \\
2,10 \\
4,20 \\
3,52 \\
6,30 \\
3,62\end{array}$ \\
\hline $\begin{array}{l}\text { Marajó } \\
(90)\end{array}$ & $\begin{array}{l}01^{\circ} 00^{\prime} 41^{\prime \prime} \mathrm{S} \\
48^{\circ} 57^{\prime} 48^{\prime \prime} \mathrm{W}\end{array}$ & $\begin{array}{l}\text { horse } \\
\text { human } \\
\text { dwelling }\end{array}$ & $\begin{array}{r}14 \\
9 \\
18\end{array}$ & $\begin{array}{r}8 \\
9 \\
32\end{array}$ & $\begin{array}{l}49,1 \\
45,5 \\
53,1 \\
48,8 \\
52,4 \\
51,1\end{array}$ & $\begin{array}{l}41,5-55,8 \\
41,7-50,0 \\
47,6-61,0 \\
44,2-54,1 \\
42,9-69,0 \\
39,5-69,7\end{array}$ & $\begin{array}{l}5,18 \\
2,35 \\
3,95 \\
3,07 \\
7,15 \\
8,60\end{array}$ \\
\hline $\begin{array}{l}\text { Boa Vista } \\
\text { (136) }\end{array}$ & $\begin{array}{l}02^{\circ} 49^{\prime} 14^{\prime \prime} \mathrm{N} \\
60^{\circ} 40^{\prime} 24^{\prime \prime}\end{array}$ & $\begin{array}{l}\text { pig sty } \\
\text { human } \\
\text { dwelling }\end{array}$ & $\begin{array}{l}42 \\
26 \\
29\end{array}$ & $\begin{array}{r}19 \\
11 \\
9\end{array}$ & $\begin{array}{l}44,5 \\
42,6 \\
46,4 \\
43,1 \\
43,7 \\
45,9\end{array}$ & $\begin{array}{l}34,8-54,2 \\
33,3-52,4 \\
39,1-56,5 \\
38,1-50,0 \\
33,3-47,8 \\
37,5-52,4\end{array}$ & $\begin{array}{l}4,26 \\
5,71 \\
4,68 \\
3,94 \\
3,63 \\
5,76\end{array}$ \\
\hline $\begin{array}{l}\text { Total } \\
(918)\end{array}$ & & & 572 & 346 & & & \\
\hline
\end{tabular}




\section{TABLE VII}

Phenotypical characteristics of populations of Anopheles albitorsis and Anopheles deaneorum (Guajará-Mirim and Rio Branco) used in Manhattan distance and UPGMA calculations

\begin{tabular}{|c|c|c|c|c|c|c|c|c|c|c|}
\hline $\begin{array}{c}\text { Populations/ } \\
\text { Characters }\end{array}$ & Baradero & $\begin{array}{l}\text { São } \\
\text { Borja }\end{array}$ & $\begin{array}{l}\text { Angra } \\
\text { Reis }\end{array}$ & Itaguaí & $\begin{array}{l}\text { Guajará- } \\
\text { Mirim }\end{array}$ & $\begin{array}{c}\text { Rio } \\
\text { Branco }\end{array}$ & Itaituba & Paraipuba & Marajó & $\begin{array}{l}\text { Boa } \\
\text { Vista }\end{array}$ \\
\hline \multicolumn{11}{|l|}{ - larvae } \\
\hline branched clypeals & 0 & 0 & 0 & 0 & 1 & 1 & 0 & 0 & 0 & 0 \\
\hline - pupae & & & & & & & & & & \\
\hline seta 0-VlI dislocated & 0 & 1 & 1 & 0 & 0 & 0 & 0 & 1 & 0 & 0 \\
\hline 0 -VI present & 0 & 1 & 0 & 1 & 0 & 0 & 1 & 0 & 0 & 1 \\
\hline duplications & 0 & 0 & 1 & 0 & 0 & 0 & 1 & 0 & 0 & 1 \\
\hline \multicolumn{11}{|l|}{ - adults } \\
\hline posterolateral tufts & 0 & 0 & 0 & 0 & 1 & 1 & 0 & 0 & 0 & 0 \\
\hline type of costa $c$ & 0 & 0 & 1 & 1 & 1 & 0 & 1 & 1 & 1 & 1 \\
\hline d & 1 & 1 & 0 & 0 & 1 & 0 & 0 & 0 & 0 & 0 \\
\hline $\mathrm{e}$ & 0 & 0 & 1 & 1 & 1 & 1 & 1 & 0 & 1 & 0 \\
\hline $\mathrm{f}$ & 1 & 1 & 0 & 0 & 1 & 1 & 0 & 0 & 0 & 0 \\
\hline g & 1 & 0 & 0 & 0 & 0 & 0 & 1 & 0 & 1 & 0 \\
\hline $\begin{array}{l}\mathrm{g} \\
\mathrm{h}\end{array}$ & 0 & 1 & 0 & 0 & l & 0 & 0 & 0 & 0 & 0 \\
\hline TaIIl $2>50 \%$ & 1 & 1 & 0 & 1 & $\hat{1}$ & 1 & 0 & 0 & 0 & 0 \\
\hline endophily $\geqslant 35 \%$ & 0 & 0 & 0 & 0 & 1 & 0 & 0 & 0 & 1 & 0 \\
\hline \multicolumn{11}{|l|}{ - distribution region } \\
\hline amazon & 0 & 0 & 0 & 0 & 1 & 1 & 1 & 0 & 1 & 1 \\
\hline coastal & 0 & 0 & 1 & 1 & 0 & 0 & 0 & 1 & 0 & 0 \\
\hline praities & 1 & 1 & 0 & 0 & 0 & 0 & 0 & 0 & 0 & 0 \\
\hline
\end{tabular}

A phenetic analysis on morphological characteristics, behaviour and distribution was carried out (Table VII). The Manhattan distance between each pair of populations was calculated and the resulting distance matrix (not shown) was transformed into a dendrogram using the UPGMA method of Sneath \& Sokal (1973). The resulting dendrogram (Fig. 6) divided the 10 populations into 2 large clusters. The first cluster had 2 groups: one that linked Baradero and São Borja and the other Guajará-Mirim with Rio Branco. The second cluster also had 2 groups: Angra, Paraipaba and Itaguaí were together in one and Boa Vista, Itaituba, and Marajó in another.

Isoenzymes - Larvae from 8 populations were analyzed. São Borja and Itaituba were not included in this study. We attemped to analyze 50 specimens per locality and not more than 2 per progeny. Nevertheless, this number was achieved in only a few enzymatic loci. Bands with identical mobility were considered identical electromorphs. They were numbered according to anodic mobility, i.e., the band nearest the origin was labelled 1 . Up to 3 different electromorphs (alleles) were found in the 10 enzymes studied, essentially the same as described in deaneorum (Rosa-Freitas, 1989).

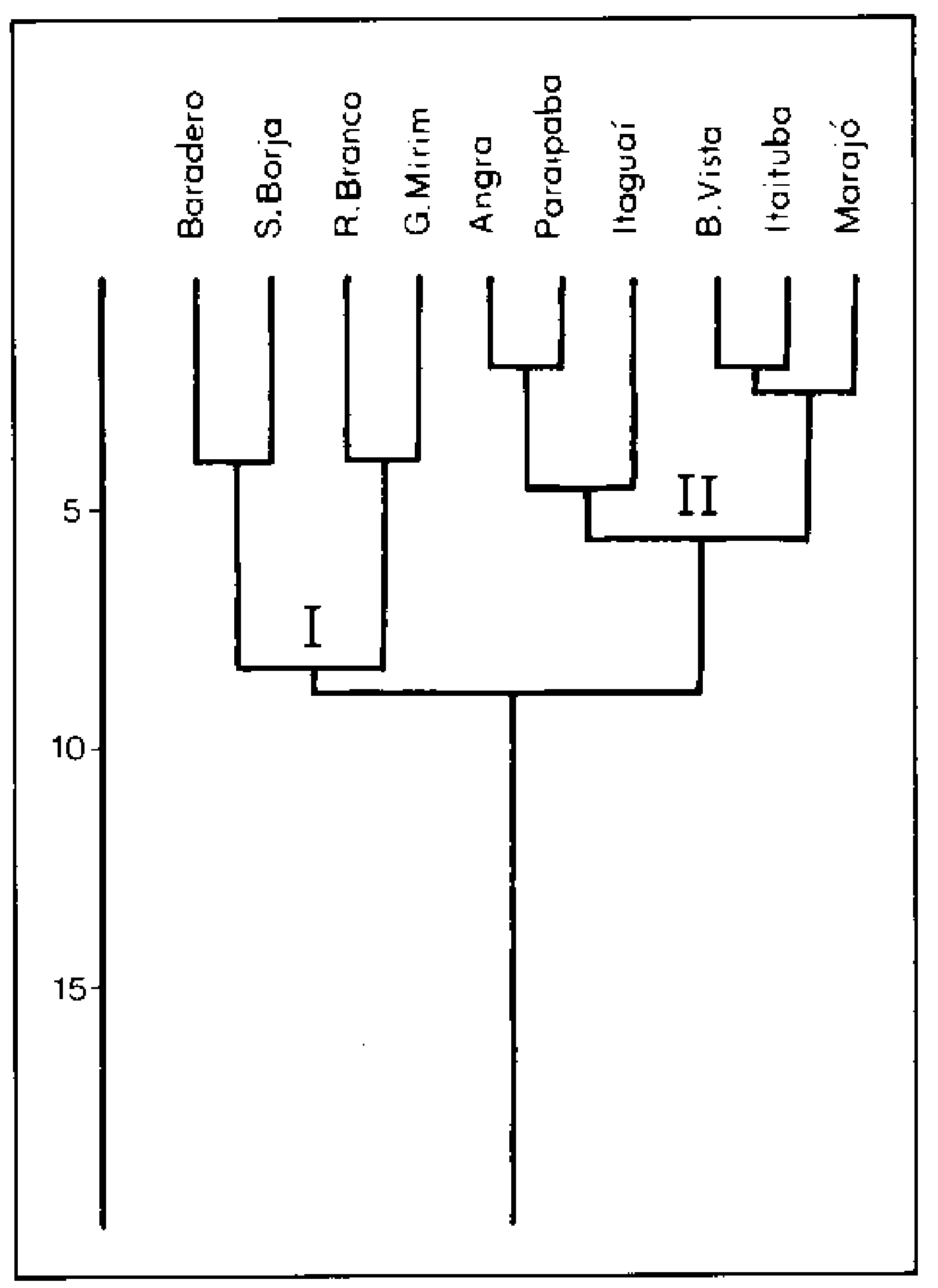

Iig. 6: dendrogram showing relationships among Anopheles albitarsis and Anopheles deaneorum (Guajará-Mirim and Rio Branco) populations obtained through Manhattan distance and UPGMA of phenotypical characteristics. 
Results obtained with larval homogenate (Fig. 7) showed 5 groupings: i) Baradero (Animal); ii) Marajó (Animal, Human and Dwelling); iii) Boa Vista (A, H and D); iv) Angra dos Reis ( $A$ and $H$ ), Itaguaí ( $A$ and $H$ ) and Paraipaba (A) and v) Rio Branco (A, H and D) and Guajará-Mirim ( $A, H$ and $D$ ), representing Anopheles deaneorum. These 5 groupings belong to 2 larger clusters called I and II, separated by a Nei's Genetic Distance (D) of 0.345 . In the cluster $I$ are $i$, ii and iii and in cluster II are iv and v (deaneorum). In I, i and ii are separated from iii by $D=0.246$, while $i$ is separated by $D=0.181$ from ii. In II, the $\mathrm{D}$ between iv and $\mathrm{v}$ is 0.223 . The $\mathrm{D}$ between types $\mathrm{A}, \mathrm{H}$ and $\mathrm{D}$ in all populations range from 0.012 to 0.090 .

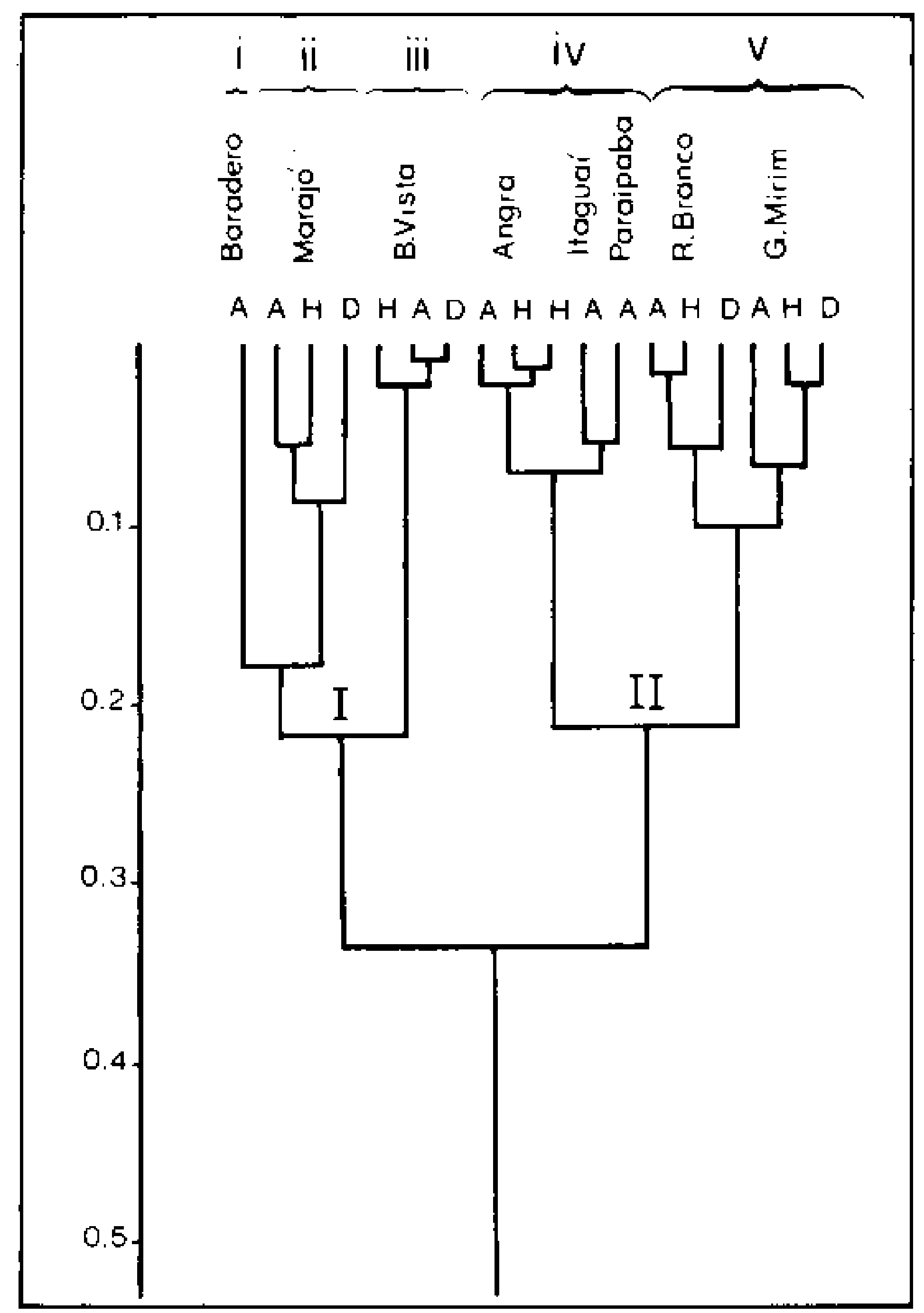

Fig. 7: dendrogram with relationships obtained through Nei's genetic distance among populations of Anopheles albitarsis (i, ii, iii and iv) and Anopheles deaneorum (v).

\section{TAXONOMIC DISCUSSION}

Based on our results Anopheles albitarsis can not be divided neither into albitarsis/domesticus nor into albitarsis/marajoara. The first division proposed by Galvão \& Damasceno
(1944), considered the percent of dark scales on the 2nd hindtarsomere not passing 55\%, the hexagonal aspect of the egg exochorion and the endophilic behaviour as exclusive characters of domesticus. In the present study the percentage of dark scales in the 2 nd hindtarsomere showed no significant variance concerning behaviour and latitude, hexagons were not found in any of the eggs, even in fresh samples seen by optical microscopy. Endophily was the only character having significant variation with latitude but it had no correlation with the distribution given to domesticus subspecies.

For the albitarsis/marajoara division, Linthicum (1988), used characteristics in female adults, male genitalia, pupa and larva that usually were very variable. Marajoara was the first name given to Marajo Island albitarsis population by Galvão \& Damasceno (1942). Among other differences found were: the absence of white rings on the apex of the 3rd foretarsus, midtarsi and 1 st hindtarsus; posterolateral tufts present from the 4th to the 7 th abdominal segments, such tufts are mentioned as yellowish; fused dorsal lobes of the male genitalia mound-like, very pilose and anal lobe bare except on the very end of the lateral portions of its base with a few minute hairs; larva showed inner anterior clypeal hair without branches and implanted wide apart; outer cly peal hairs with vestigial branches, as observed by us in type-material from the Entomological Collection of Faculty of Public Health of University of São Paulo (larval exuvia no. E-2120, slide no. 817). Two years later Galvão (1944) recognized marajoara as "species inquirenda", an anomalous finding, a mosquito that was caught only once in Marajo Island, in spite of many later attempts. In 1944, when domesticus was described no relationship was given to it and the former marajoara. Our results showed that the isolated population of the Marajó Island has some remarkable characteristics such as its high endophily and Nei's genetic distance from the type-locality which are enough for it to be given at least a subspecific status. Anyway, although its status is not presently well defined, marajoara or domesticus is a name that should be restricted to Marajó Island populations.

From isoenzymatic analysis we could group the 10 populations studied as Baradero, Marajó, Boa Vista, Angra/Itaguai/ Paraipaba and Guaja- 
rá-Mirim/ Rio Branco with $\mathrm{D}<0.11(0.012$ to 0.108 ) for intrapopulational variations and distances among the 5 subspecies ranging from 0.181 to 0.246 . These 5 subspecies belong to 2 groups called I and II. Group I, with Boa Vista, Baradero and Marajó, are 0.345 distant from [I, with Guajará-Mirim/ Rio Branco and Angra/ Itaguai/ Paraipaba. This value of D is sufficient to consider I and $I I$ as cryptic species according to Avise (1974), Bullini (1982) and Steiner et al. (1982).

Both phenetic and isoenzymatic analysis divided the 10 populations in 2 big clusters I and II, although the position of the groups within the clusters was different. Phenoty pically, I cluster contained Baradero, São Borja and Guajará-Mirim/ Rio Branco and II, Angra/ Itaguai/ Paraipaba and Marajó, Boa Vista and Itaituba. Isoenzymatically cluster I contained Baradero, Marajó and Boa Vista and II contained Angra/ Itaguaí/ Paraipaba and Guajará-Mirim/ Rio Branco (Itaituba and São Borja were not assayed). The cohesion of Angra/ Itaguai/ Paraipaba and Guajará-Mirim/ Rio Branco was demonstrated by being clustered together in single groups in both studies. Phenotypical analysis positions Baradero and São Borja closer to Guajará-Mirim/ Rio Branco than by isoenzymes where they are in separate clusters. Marajó and Boa Vista were grouped in the same cluster in both analyses.

Steiner et al. (1982) studied 6 enzymatic loci and chromosomal maps for 10 Anopheles albitarsis populations. Where marked differences were found in isoenzymes (malic enzyme ME. E.C.1.1.1.40 in Araraquara and hydroxybutyrate dehydrogenase - HBDH. E.C.1.1.1. 30 in Macapá) chromosomal mapping suggested the existence of cryptic species. So, they concluded for the presence of 3 types or species calling the Macapá population as albitarsis sensu strictu or species a, Araraquara population as albitarsis limai or species $\mathrm{c}$ and the rest as albitarsis domesticus or species $\mathrm{b}$. Correlation with the $\mathrm{C}, \mathrm{B} 1$ and $\mathrm{B} 2$ chromosomal types of Kreutzer et al. (1976) was not verified. Combining the isoenzyme and chromosome results, Steiner et al., (1982) made a distribution map where albitarsis (species a) would be of coastal distribution, limai (species c) of the hinterland and domesticus (species b) sympatric to both. Nevertheless, limai is a name that can not be rehabilitated. It was created from a mix-up in the figures of albitarsis and darlingi eggs, made by Root in 1926 (Causey et al., 1942). Limai was described as an albitarsis subspecies only because of this differential character of the eggs by Galvão \& Lane (1937) that was in fact never seen again. The same mistake led to the description of the paulistensis variety of darlingi (Galvão et al., 1937).

From these previous papers (Kreutzer et al., 1976; Steiner et al., 1982) a correlation can be observed among the coastal groups: B2 of Kreutzer, b of Steiner and Angra/ Itaguai/ Paraipaba of the present study and also with $C$ of Kreutzer and its neighbour Boa Vista of this study (Fig. 8),

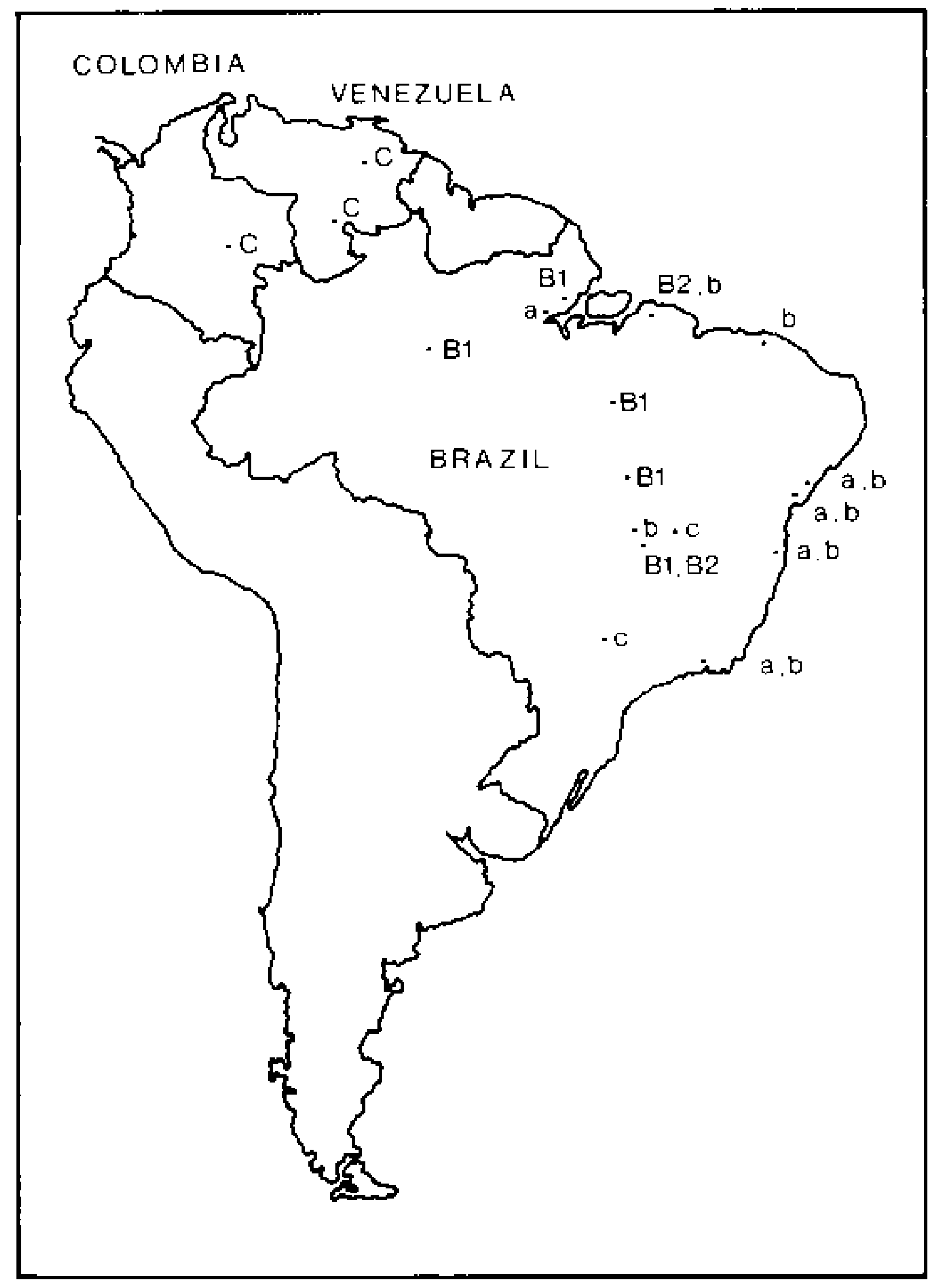

Fig. 8: data from literature concerning chromosomal and isoenzymatic patterns of Anopheles albitarsis.

We therefore, separate the 10 populations into 5 possible taxons that could be classified as subspecies according to their Nei's genetic distance (Fig. 9):

\section{In group I:}

i) a meridional population, Baradero and São Borja, morphologically characterized by the absence of presector pale in wing costa of the great majority of specimens; 
ii) a population restricted to Marajó Island, with the characteristic of having the highest endophilic behaviour;

iii) a septentrional population represented by Boa Vista, without diagnostic morphological or isoenzymatic characters. There is a possibility that it belongs to $\mathrm{C}$ chromosomal type of Kreutzer et al. (1976), as Villavicencio, Colombia and Maripa and Bolivar, Venezuela;

\section{In group II:}

iv) a population of predominant coastal distribution, Angra/ Itaguai/ Paraipaba, that by previous reports in the literature would act as a good malaria vector although in this region it is not highly endophilic or anthropophilic.

v) a morphologically distinct population described as a new species Anopheles deaneorum (Rosa-Freitas, 1989), represented in the study by Guajará-Mirim and Rio Branco, with branched outer anterior clypeal hairs in the 4th instar larvae and paler cuticle and postero. lateral tufts of dark scales begining in the 4th or 5 th abdominal tergite in adults.

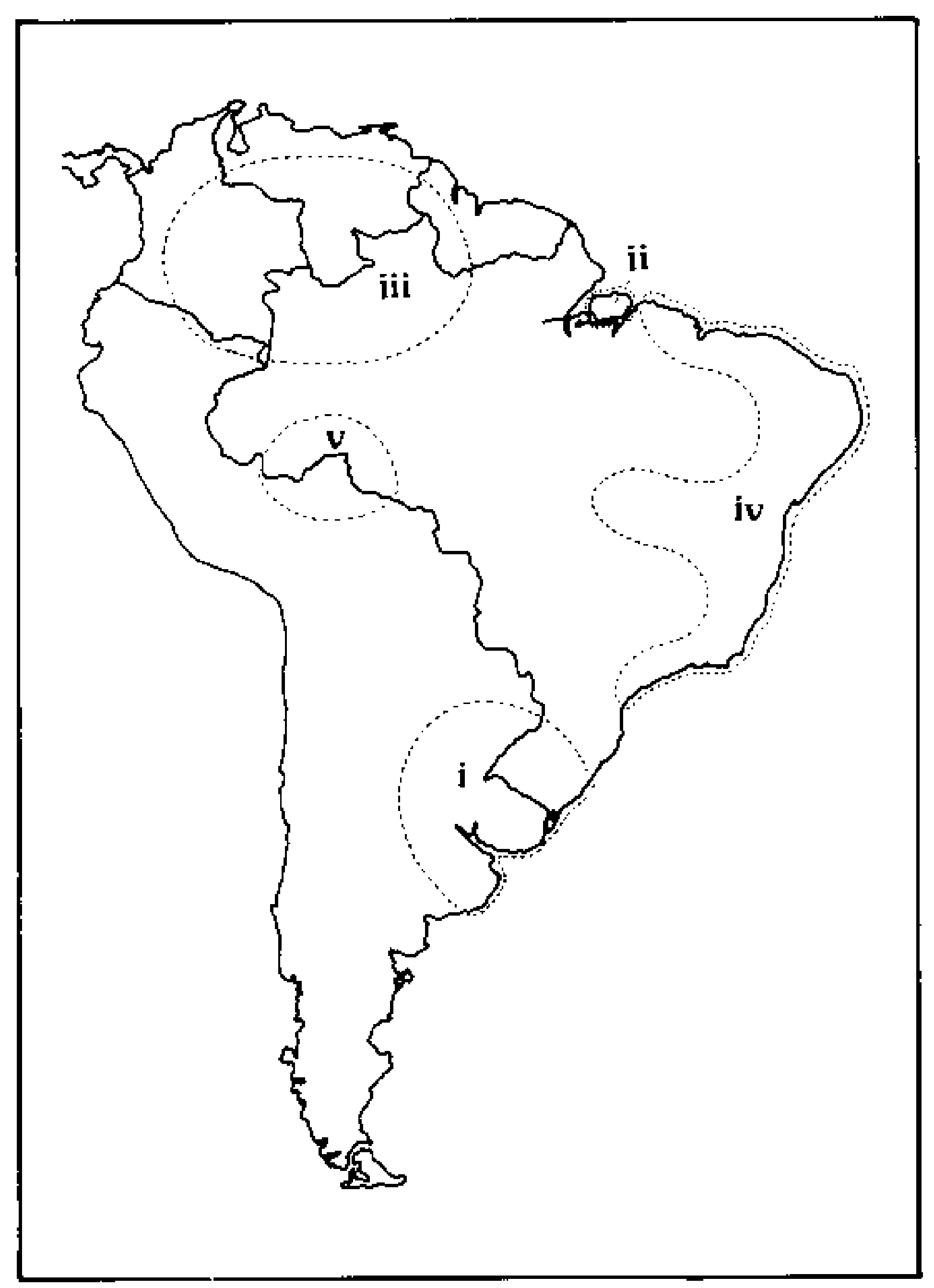

Fig. 9: probable distribution of 4 groups of Anopheles albitarsis (i, ii, iii and iv) and Anopheles deaneorum (v).

\section{ACKNOWLEDGEMENTS}

To Mr Pery Sant'Anna de Souza, Entomologist of SUCAM, for mosquito capture in some localities; Dr Ricardo Lourenço-de-Oliveira for orientation and suggestions; to Col Patrick Mc Greevy and $\mathrm{Mj}$ Terry Klein of the U. S. Army Medical Research Unit for the opportunity of visiting Costa Marques; to Dr Richard Cibulskis, Liverpool School of Tropical Medicine, for computer software used in the analysis of the results; to Dr Wanderley de Souza, Federal University of Rio de Janeiro, for electron microscope facilities; to Teresa Fernandes da Silva, Marcia Gonçalves de Castro and Elisa Cupolillo for technical support.

\section{REFERENCES}

AVISE, J. C., 1974. Systematic value of electrophoretic data. Syst Zool, 23: 465-481.

BOYD, M. F,, 1926. Studies of the epidemiology of malaria in the coastal lowlands of Brazil made before and after the execution of control measures. Am. Journ. Hyg., Monographic series 5.

BULLINI, L., 1982. Enzyme variants in the identification of parasites and vectors: Methodological aspects of eletrophoretic approach. In New approaches to the identification of parasites and their vectors. Tropical Diseases series no. 5/ WHO.

CADENA, M. A., 1938. Disseccion de mosquitos Anopheles. Rev. Fac. Nac., Bogotá, 7: 328-333.

CAUSEY, O. R.; DEANE, L. M. \& DEANE, M. P., 1942. Note clarifying the status of Anopheles albitarsis and Anopheles darlingi. Proc. Entom. Soc. Washington, 44: 122-126.

COUTINHO, J. O., 1942. Contribuição ao estudo dos transmissores da malária no Distrito Federal, Brasil. Arq. Hig., 12:7.13.

COUTINHO, J. O., 1946. Anofelinos do Rio de Janeiro (Distrito Federal) com referência aos transmissores de malária. O Hospital, 30:651-662.

DEANE, L. M.; CAUSEY, O. R. \& DEANE, M. P., 1948. Notas sobre a distribuiçāo e a biologia dos anofelinos das Regiões Nordestina e Amazônica do Brasil. Rev. Serv. Esp. Saúde Pública, 1:827965.

FONSECA, J. A. B. \& UNTI, O., 1943. Infecção experimental de anofelinos de regiões indenes à malária. Folia Clin. Biol., 15:43-52.

FREITAS, G., 1942. Pesquisas sobre a transmissāo da malária na Baixada Fluminense. Rev. Med. Cir. Brasil., 5: 15-20.

GABALDON, A., 1940. Nota sobre habitos diurnos, temperatura de yacimientos larvarios y yacimientos larvarios artificiales de Anopheles de Venezuela. Gac. Med. Caracas, 5:72-75.

GALVĀO, A. L. A., 1944. Chaves para a determinaçāo das espécies do subgênero Nyssorhynchus do Brasil. Arq. Hig. Saúde Púb., 8:141-153.

GALVÄO, A. L. A. \& DAMASCENO, R. G., 1942. Sobre um novo anofelino da Ilha de Marajó, Anopheles (Nyssorhynchus) marajoara. Folia Clin. Biol., Sāo Paulo, 14:60-66. 
GALVÃO, A. L. A. \& DAMASCENO, R. G., 1944. Observações sobre anofelinos do complexo albitarsis. An. Fac. Med. Univ. Säo Paulo, 20:73-87.

GALVĀO, A. L. A.\& LANE, J., 1937. Notas sobre os Nyssorhynchus de São Paulo. VII. Estudo sobre as variedades deste grupo com a descrição de Anophe. les (Nyssorhynchus) albitarsis var. limai. An. Fac. Med. Univ. Säo Paulo, 13: 211-238.

GALVĀO, A. L. A.; LANE, J. \& CORREA, R. R., 1937. Notas sobre os Nyssorhynchus de São Paulo. V. Nota sobre os Nyssorhynchus de Novo Otjente. Rev. Biol. Hig., 8:37.45.

GODOY, A.; LOBO, A. \& CRUZ Fo, O., 1930. Sur les anophelines qui transmettent le paludisme au Brèsil. C. R. Soc. Biol., 105:731.

GODOY, A. \& PINTO, C. 1923. Estudos sobre a malária no município de Campos. Brazil Médico, 37 : 29.

HARBACH, R. E. \& KNIGHT, K. L., 1980. Taxonomists' Glossary of Mosquito Anatomy. Elsevier Pub., Amsterdam, 415 p.

HARBACH, R. E. \& KNIGHT, K. L., 1981. Corrections and additions to Taxonomists' Glossary of Mosquito Anatomy. Mosq. Syst., 13:201-217.

KUMM, H. W., 1932. Observations on two malaria vectors and distribution records of other Anopheles in the States of Bahia and Sergipe, Brazil. Ann. Trop. Med. Parasitol., London, 26:1-6.

KREUTZER, R. D.; KITZMILLER, J. B. \& RABBANI, M. G., 1976 Cytogenetically distinguishable sympatric and allopatric populations of the mosquito Anopheles albitarsis. Acta Amaz., 6: 473482.

LINTHICUM, K. J., 1988. A revision of the Argyritarsis section of the subgenus Nyssorhynchus of Anopheles. Mosq. Syst., 20:98-271.

LOURENÇO-DE-OLIVEIRA, R. \& HEY DEN, R., 1986. Alguns aspectos da ecologia dos mosquitos de uma área de planície (Granjas Calábria) em
Jacarepaguá, Rio de Janeiro. IV - Pteferências alimentares quanto ao hospedeiro $\mathrm{e}$ freqüência domiciliar. Mem. Inst. Oswaldo Cruz, 81:15-28.

MOMEN, H. \& SALLES, C. A., 1985. Enzy me markers for Vibrio cholerae: identification of classical, eltor and environmental strains. Trans. $R$. Soc. Trop. Med. Hyg., 79:773-776.

RIOS, R. J.; NASCIMENTO, L. P. \& OLIVEIRA, A. C., 1984. Complexo Anopheles albitarsis: impossibilidade de separá-lo em 2 subespécies Anopheles albitarsis albitarsis e Anopheles albitarsis domesticus. Rev. Bras. Biol., 44: 461-465.

ROOT, F. M., 1926. Studies on Brazilian mosquitoes. I. The anophelines of the Nyssorhynchus group. Amer. J. Hig., 6:684-717.

ROSA-FREITAS, M. G., 1988. Anopheles albitarsis Lynch-Arribálzaga, 1878. Um estudo comparativo de caracteres morfologicos, bioquímicos e compor. tamentais de populaçōes de dez localidades. Tese de Mestrado. Instituto Oswaldo Cruz, Rio de Janeiro.

ROSA.FREITAS, M. G., 1989. Anopheles (Nyssorhynchus) deaneorum, a new species in the albitarsis complex. Mem. Inst. Oswaldo Cruz, 84: $535-543$.

ROSA-FREITAS, M. G. \& DEANE, L. M., 1989. The neotype of the Anopheles albitarsis. Mem. Inst. Oswaldo Cruz, 84:289-302.

SCHIAVI, A., 1945. Nota sobre mosquitos vetores em Iguape. Arq. Hig. Saúde Púb., 10:67-75.

SNEATH, P. H. A. \& SOKAL, R. R., 1973. Numerical Taxonomy. W. H. Freeman, San Francisco. 573 p.

STEINER, W. W. M.; NARANG, S.; KITZMILLER, J. B. \& SWOFFORD, D. L., 1982. Genetic divergence and evolution in neotropical Anopheles (subgenus Nyssorhynchus). Recent Developments in the Genetics of Insect Disease Vectors. Stipes Pub. Cy, Illinois, 523-551 p. 